\title{
IRRADIATION-ASSISTED STRESS CORROSION CRACKING OF AUSTENTTIC STAINLESS STEELS: RECENT PROGRESS AND NEW APPROACHES*
}

H. M. Chung, W. E. Ruther, J. E. Sanecki, A. Hins, N. J. Zaluzec, and T. F. Kassner

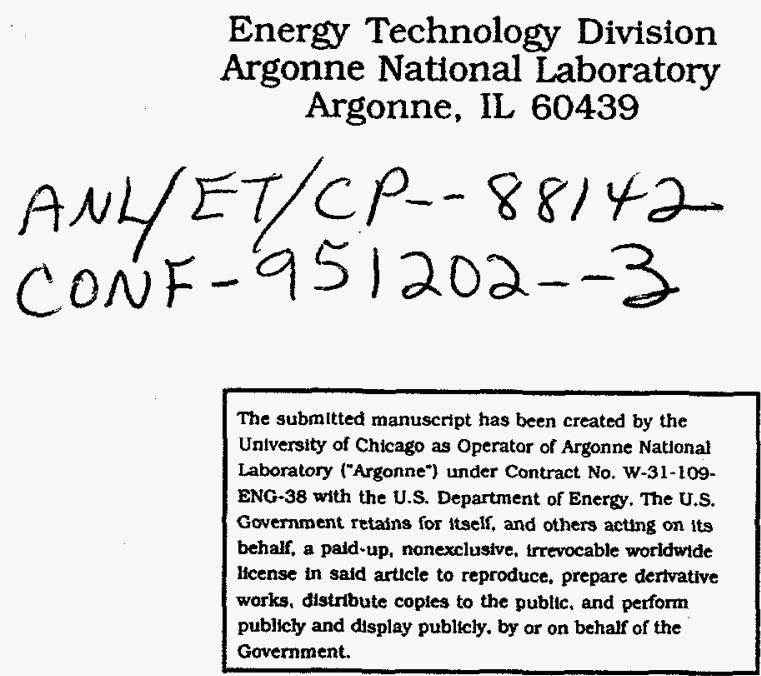

RECEIVED

OC. 301996

OSTI

September 1996

\section{DISCLAIMER}

This report was prepared as an account of work sponsored by an agency of the United States Government. Neither the United States Government nor any agency thereof, nor any of their employees, makes any warranty, express or implied, or assumes any legal liability or responsibility for the accuracy, completeness, or usefulness of any information, apparatus, product, or process disclosed, or represents that its use would not infringe privately owned rights. Reference herein to any specific commercial product, process, or service by trade name, trademark, manufacturer, or otherwise does not necessarily constitute or imply its endorsement, recommendation, or favoring by the United States Government or any agency thereof. The views and opinions of authors expressed herein do not necessarily state or reflect those of the United States Government or any agency thereof.

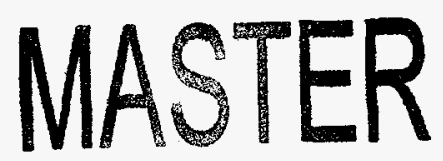

To be published in the Journal of Nuclear Materials (as Proceedings of International Symposium on Advanced Materials and Technology for the 21st Century, Honolulu, Dec. $13-15,1995)$

*Work supported by the U.S. Nuclear Regulatory Commission, Office of Nuclear Regulatory Research. 


\section{DISCLAIMER}

Portions of this document may be illegible in electronic image products. Images are produced from the best available original document. 


\title{
IRRADIATION-ASSISTED STRESS CORROSION CRACKING OF AUSTENITIC STAINLESS STEELS: RECENT PROGRESS AND NEW APPROACHES*
}

\author{
H. M. Chung, W. E. Ruther, J. E. Sanecki, A. Hins, N. J. Zaluzec, and T. F. Kassner \\ Energy Technology Division \\ Argonne National Laboratory \\ Argonne, IL 60439, USA
}

\begin{abstract}
Irradiation-assisted stress corrosion cracking (IASCC) of several types of BWR field components fabricated from solution-annealed austenitic stainless steels (SSs), including a core internal weld, were investigated by means of slow-strain-rate test (SSRT), scanning electron microscopy (SEM), Auger electron spectroscopy (AES), and field-emission-gun advanced analytical electron microscopy (FEG-AAEM). Based on the results of the tests and analyses, separate effects of neutron fluence, tensile properties, alloying elements and major impurities identified in the American Society for Testing and Materials (ASTM) specifications, minor impurities, water chemistry, and fabrication-related variables were determined. The results indicate strongly that minor impurities not specified by the ASTM-specifications play important roles, probably through a complex synergism with grain-boundary $\mathrm{Cr}$ depletion. These impurities, typically associated with steelmaking and component fabrication processes, are very low or negligible in solubility in steels and are the same impurities that have been known to promote intergranular SCC significantly when they are present in water as ions or soluble compounds. It seems obvious that IASCC is a complex integral problem which involves many variables that are influenced strongly by not only irradiation conditions, water chemistry, and stress but also iron and steelmaking processes, fabrication of the component, and joining and welding. Therefore, for highstress components in particular, it would be difficult to mitigate IASCC problems at high fluence based on the consideration of water chemistry alone, and other considerations based on material composition and fabrication procedure would be necessary as well.
\end{abstract}

\section{Introduction}

Failures of core internal components in both BWRs and PWRs have increased in recent years after accumulation of relatively high irradiation damages. The general pattern of these failures indicates that as neutron fluence increases, various nonsensitized austenitic stainless steels (SSs) become susceptible to intergranular failure. Although most failed components can be replaced, some safety-significant structural components would be very difficult or impractical to replace. Therefore, the structural integrity of these components has been a subject of concern, and extensive research has been conducted to provide an understanding of this type of degradation, which is commonly known as irradiationassisted stress corrosion cracking (IASCC). ${ }^{1-26}$

Primary effects of irradiation include the alteration of microchemistry, microstructure, and mechanical properties of the structural material itself, usually fabricated from ASTM Type 304,316 , or 348 SSs. Neutron irradiation also alters the water chemistry, in particular near the grain-boundary surfaces in a crack tip. Irradiation produces defects and defect clusters in grain matrices, and alters the dislocation network, dislocation loop, and dislocation channel structures, leading to radiation-induced hardening. Irradiation also leads to changes in the stability of second-phase precipitates and the local alloy chemistry near grain boundaries, precipitates, and defect clusters. Grain-boundary microchemistry that differs significantly from that of the bulk composition can be produced in association with not only radiation-induced segregation (RIS) but also thermally driven equilibrium and nonequilibrium segregation of alloying and impurity elements.

\footnotetext{
*Work supported by the U.S. Nuclear Regulatory Commission, Office of Nuclear Regulatory Research.
} 
Irradiation-induced grain-boundary depletion of $\mathrm{Cr}$ has been considered for many years as the primary metallurgical process that causes IASCC. One of the most important factors that has been considered by many investigators to support the $\mathrm{Cr}$-depletion mechanism is the observation that dependence on water chemistry (i.e., oxidizing potential) of intergranular stress corrosion cracking (IGSCC) of nonirradiated thermally sensitized material and of IASCC of BWR-irradiated solution-annealed material is similar (e.g., see Refs. 1 and 2). However, contrary to expectations based on the Cr-depletion mechanism, cracking of control rod cladding and baffle plate bolts has been reported at numerous PWRs (i.e., under nonoxidizing potential). Also, the susceptibility of PWRirradiated components to IASCC has been shown clearly from expanding-mandrel11 and slow-strain-rate tensile (SSRT) ${ }^{26}$ tests in PWR ${ }^{11}$ or PWR-simulated water 26 , although PWR water chemistry falls well within the range of protective electrochemical potential (ECP). 4,25 Other investigators have implicated RIS of ASTM-specified impurities such as $\mathrm{Si}, \mathrm{P}$, and $\mathrm{S}$ as the primary process that causes IASCC. $3,6,7,9,11$ The superior resistance of one heat of Type 348 SS that is substantially low in $\mathrm{C}, \mathrm{Si}, \mathrm{P}$, and S seemed to provide direct evidence for this, 11 and the same rationale was extended to Type 304 SS. However, in direct contradiction, many investigators have reported in recent years results indicating that resistance of high-purity (HP) heats (low in $\mathrm{C}, \mathrm{Si}, \mathrm{S}$, and P) of Type $304 \mathrm{SS}$ is no better than that of commercial-purity (CP) materials. ${ }^{6-9,14,19,23}$ Therefore, the role of grain-boundary segregation of $\mathrm{Si}, \mathrm{P}$, and $\mathrm{S}$ appears to be not well established.

In general, IASCC is characterized by strong heat-to-heat variation in susceptibility, in addition to strong effects of irradiation condition, material type, and grade, even among materials of virtually identical chemical compositions. This indicates that the traditional interpretation based on the role of grain-boundary segregation of the usual impurities identified in the ASTM specifications or on $\mathrm{Cr}$ depletion cannot explain well the mechanism of IASCC. Thus, although significant grain-boundary $\mathrm{Cr}$ depletion is believed by most investigators to play an important role, it has been suspected that other important processes may have been overlooked which could be associated with other minor impurity elements not identified in the ASTM specifications. In this paper, we report a summary of the results from slow-strain-rate test (SSRT) and microstructural analyses by Auger electron spectroscopy (AES) and field-emission-gun advanced analytical electron microscopy (FEG-AAEM) that have been conducted at Argonne National Laboratory in the past several years on discharged BWR components. Emphasis of the work has been to investigate the roles of water chemistry, major and minor impurities, and other metallurgical processes that occur during fabrication of actual components. The results are discussed in comparison with results of other similar investigations to provide a better understanding of the separate effects, and eventually, the integral mechanism(s) of IASCC.

Table 1. Material type, chemical composition (in wt.\%), and fluence of BWR components

\begin{tabular}{|c|c|c|c|c|c|c|c|c|c|c|c|}
\hline \multirow[b]{2}{*}{ Heat ID } & \multicolumn{9}{|c|}{ Composition (wt.\%) } & \multirow{2}{*}{$\begin{array}{c}\text { Source } \\
\text { Code }\end{array}$} & \multirow{2}{*}{$\begin{array}{c}\text { Fluence } \\
\left(10^{21} \mathrm{n} \cdot \mathrm{cm}^{-2}\right)\end{array}$} \\
\hline & $\mathrm{Cr}$ & $\mathrm{Ni}$ & $\overline{M n}$ & $\bar{C}$ & $\bar{N}$ & $\bar{B}$ & $\overline{\mathrm{Si}}$ & $\bar{P}$ & $\mathrm{~S}$ & & \\
\hline HP304-A & 18.50 & 9.45 & 1.53 & 0.018 & 0.100 & $<0.001$ & $<0.03$ & 0.005 & 0.003 & $\mathrm{~V}$-ATa & $0.2-1.4$ \\
\hline HP304-B & 18.30 & 9.75 & 1.32 & 0.015 & 0.080 & $<0.001$ & 0.05 & 0.005 & 0.005 & $\mathrm{~V}-\mathrm{AT} \mathrm{T}^{\mathrm{a}}$ & $0.2-1.4$ \\
\hline HP304-CD & 18.58 & 9.44 & 1.22 & 0.017 & 0.037 & 0.001 & 0.02 & 0.002 & 0.003 & $\mathrm{~V}-\mathrm{AT}^{\mathrm{a}}$ & $0.2-1.4$ \\
\hline HP304-CD & 18.58 & 9.44 & 1.22 & 0.017 & 0.037 & 0.001 & 0.02 & 0.002 & 0.003 & QC-ATa & 2.0 \\
\hline CP304-A & 16.80 & 8.77 & 1.65 & $0.08^{b}$ & 0.052 & - & 1.55 & $0.045^{b}$ & $0.030^{b}$ & $B L-A T C$ & $0.2-2.0$ \\
\hline CP304-B & $18-20$ & $8-10$ & $2.00^{b}$ & $0.08^{b}$ & - & - & $1.00^{\mathrm{b}}$ & $0.045^{b}$ & $0.030^{b}$ & LC-S ${ }^{d}$ & $0.5-2.6$ \\
\hline CP348a & 17.4 & 11.5 & 1.56 & 0.074 & 0.042 & - & 0.34 & 0.007 & 0.009 & SMTe & $\approx 1.5$ \\
\hline HP348b & 17.7 & 11.1 & 1.65 & 0.041 & 0.008 & - & 0.19 & 0.002 & 0.007 & SMTe & $=3.5$ \\
\hline
\end{tabular}

aHigh-purity neutron absorber tubes, $O D=4.78 \mathrm{~mm}$, wall thickness $=0.63 \mathrm{~mm}$, composition measured before service.

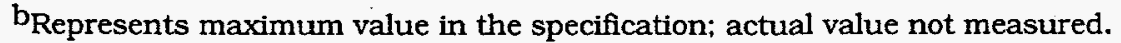

${ }^{c}$ Commercial-purity absorber tubes, $O D=4.78 \mathrm{~mm}$, wall thickness $=0.79 \mathrm{~mm}$, composition measured after service.

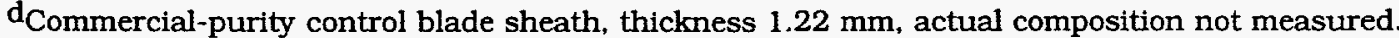

eSwelling mandrel tube irradiated in $7 \times 7$ fuel assembly in BWR KKP-1. 
Slow-Strain-Rate Tensile Test and Microchemical Analyses

Susceptibility to IASCC or mechanically induced intergranular cracking (IGC) is usually measured by SSRT tests of irradiated specimens, either in air or argon, in simulated BWR, or under PWR conditions. In the present work, SSRT specimens of sheet or tubular geometry were prepared from several types of discharged BWR components. The material type, fast neutron fluence, and chemical composition of the high- and commercial-purity (HP and CP) grade components are given in Table 1. A description of the typical procedures for hot-cell SSRT tests has been reported elsewhere.7,8,25 SSRT tests were conducted in air and in simulated LWR water at $289^{\circ} \mathrm{C}$ at a fixed strain rate of $1.65 \times 10^{-7}$ $\mathrm{s}^{-1}$. SSRT tests in water were conducted at dissolved oxygen (DO) concentrations of $\approx 8$, $\approx 0.3$, and $<0.02 \mathrm{ppm}$. Dissolved oxygen was controlled by purging deaerated feedwater with an $\mathrm{N}_{2} / \mathrm{O}_{2}$ mixture and was measured on the effluent side. Effluent ECP values were determined by sequential measurements on working electrodes of Type 304 SS and platinum. The reference electrode located at the outlet of the autoclave was $0.1 \mathrm{M}$ $\mathrm{KCl} / \mathrm{AgCl} / \mathrm{Ag}$. When the stainless steel ECP was stabilized, the SSRT test was initiated. During the test, ECP was measured periodically until the specimen fractured.

Grain-boundary microchemistry were analyzed with a JEOL-JAMP10 shielded scanning Auger microscope (SAM) on specimens charged with hydrogen and fractured insitu in the ultrahigh vacuum of the SAM. Auger electron sectroscopy (AES) is superior to other techniques for determining grain-boundary compositions of most nonmetallic elements and many metallic elements. Limited analysis of grain-boundary microchemistry has been conducted with a Vacuum Generator Model HB603 FEG-AAEM.

\section{Effect of Exposure to High-Temperature Water}

Intergranular cracking that is characteristic of IASCC occurs only in the presence of water. Some investigators have reported intergranular-like fracture surfaces produced in inert atmosphere in highly irradiated PWR components. 16 However, a careful examination of the high-magnification fracture surfaces in the report indicates that the morphology resembles dislocation-channeling-induced fracture characteristic of highly irradiated austenitic stainless steel rather than true intergranular fracture. There has also been a report of localized intergranular fracture limited to the narrow band underneath the oxygen-rich corrosion layer produced in inert gas. 17 However, this type of localized intergranular fracture does not seem to represent the through-wall crack propagation by general intergranular fracture in IASCC, which extends far from corrosion layer. Therefore, many investigators accept that a water environment is a necessary condition and IASCC is commonly attributed to some mechanism that alters the microchemistry of the grain boundaries to make them increasingly susceptible to aqueous corrosive attack as fluence increases.

Purely mechanical intergranular failure was observed at room temperature in air or in inert atmosphere in unirradiated and irradiated specimens only after charging with hydrogen. Heat-to-heat variation in the susceptibility to this type of intergranular cracking was significant. Moreover, the susceptibility was inversely proportional to susceptibility to IGSCC in water, which was measured at DO level of $\approx 0.3 \mathrm{ppm}$ in simulated BWR water (see Fig. 1). A similar occurrence of hydrogen-induced intergranular cracking in irradiated austenitic stainless steels in inert environment at $\approx 290^{\circ} \mathrm{C}$ has not been reported, however. The results in Fig. I(A) seem to indicate strongly that mechanisms of IASCC and hydrogeninduced intergranular cracking (at room temperature) are quite different; thus, the exact role of hydrogen in IASCC at $288-340^{\circ} \mathrm{C}$ is not clear at this time. Mummert et al. have reported that diffusivity of hydrogen in austenitic stainless steels and Ni-base alloys is sensitive to Ni contents. 27 According to this report, hydrogen diffusion is expected to be more pronounced along grain boundaries higher in Ni concentration. Consistent with this effect, susceptibility of the irradiated Type 304 stainless steels to hydrogen-induced intergranular cracking appears to increase with grain-boundary Ni content; see Fig. 1(B). It should be noted, however, that $\mathrm{Ni}$ content is one of many material characteristics that vary in the materials shown in Fig. 1. 

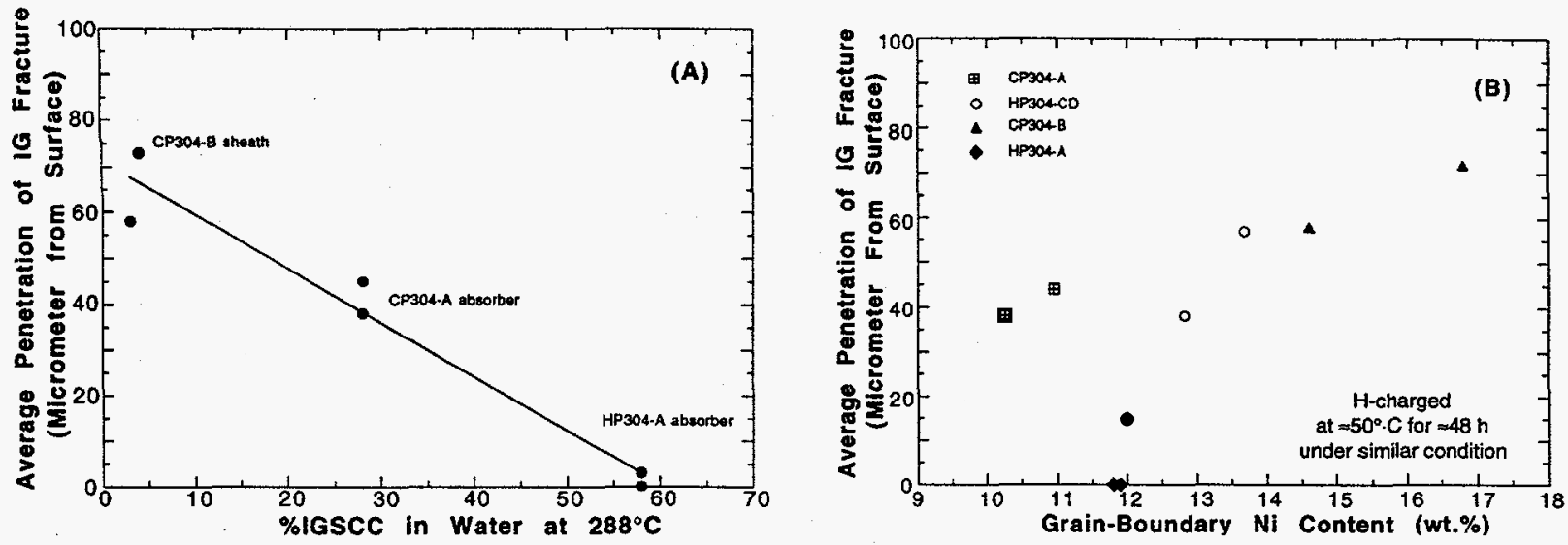

Fig. 1. Susceptibility of BWR components irradiated to $\approx 2.0 \times 10^{21} \mathrm{n} \mathrm{cm}^{-2}$ (E > $1 \mathrm{MeV}$ ) to hydrogen-induced intergranular cracking at $23^{\circ} \mathrm{C}$ in vacuum as function of (A) susceptibility to IGSCC at $288^{\circ} \mathrm{C}$ in BWR-simulated water at $D O$ of $\approx 03 \mathrm{ppm}$ and $(\mathrm{B})$ grain-boundary Ni concentration.

\section{Effect of Neutron Fluence}

The percent IGSCC measured in the BWR specimens has been plotted in Fig. 2 as a function of fast neutron fluence. Similar results reported by BWR vendors are also shown in the figure. All data in the Fig. 2(A) were obtained from BWR components at a comparable strain rate of $\approx 2 \times 10^{-7} \mathrm{~s}^{-1}$ in water containing $\approx 0.3 \mathrm{ppm}$ dissolved $O$. Similar results obtained for DO of $\approx 0.2-32 \mathrm{ppm}$ are compiled in Fig. 2(B) for comparison. The Figures 2(A) and 2(B) indicate that the $\mathrm{CP}$ control blade sheath is very resistant to IASCC. Susceptibility of the HP absorber tube, on the other hand, is greater than those of other materials. Therefore, a comparative microstructural characterization of the CP sheath and the HP absorber tube specimens was considered to be ideal for providing a mechanistic understanding, and extensive analysis by AES was therefore conducted.
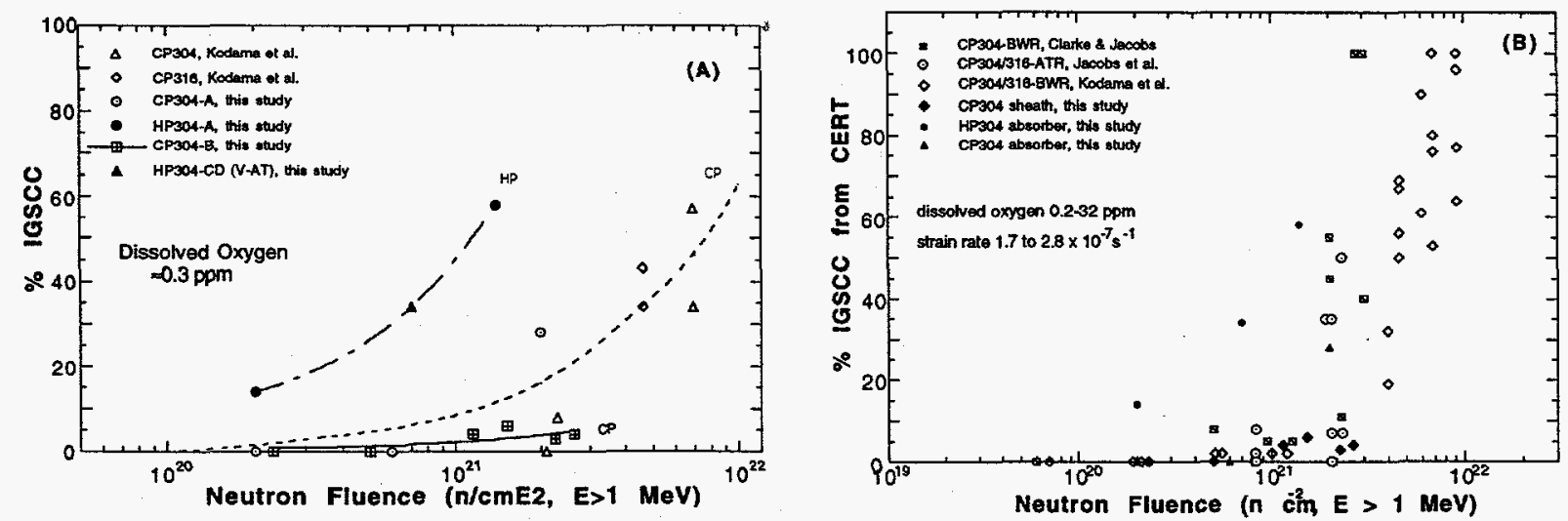

Fig. 2. Percent IGSCC vs. fluence for Type 304 SS and CP 316 SS from SSRT tests at $289^{\circ} \mathrm{C}$ in water at $D O$ of $(A) \approx 0.3 \mathrm{ppm}$ only and $(B) \approx 0.2-32 \mathrm{ppm}$.

\section{Effect of Irradiation Hardening}

The susceptibility to IGSCC is plotted in Fig. 3 as a function of yield strength measured at $289^{\circ} \mathrm{C}$ in air. The figure indicates that susceptibility increases generally as yield strength increases, indicating that grain boundaries become increasingly more susceptible to cracking as yielding in grain matrices become more difficult. However, for materials of 
comparable yield strength, variation in susceptibility is significanmt. For example, CP 304 SS sheath exhibited excellent resistance to IG cracking despite more pronounced irradiation-induced hardening for comparable fluence. For a similar yield strength of $\approx 800$ $\mathrm{MPa}$, percent IGSCC could be as high as $100 \%$ or as low as $\approx 3 \%$, depending on material composition and structure.

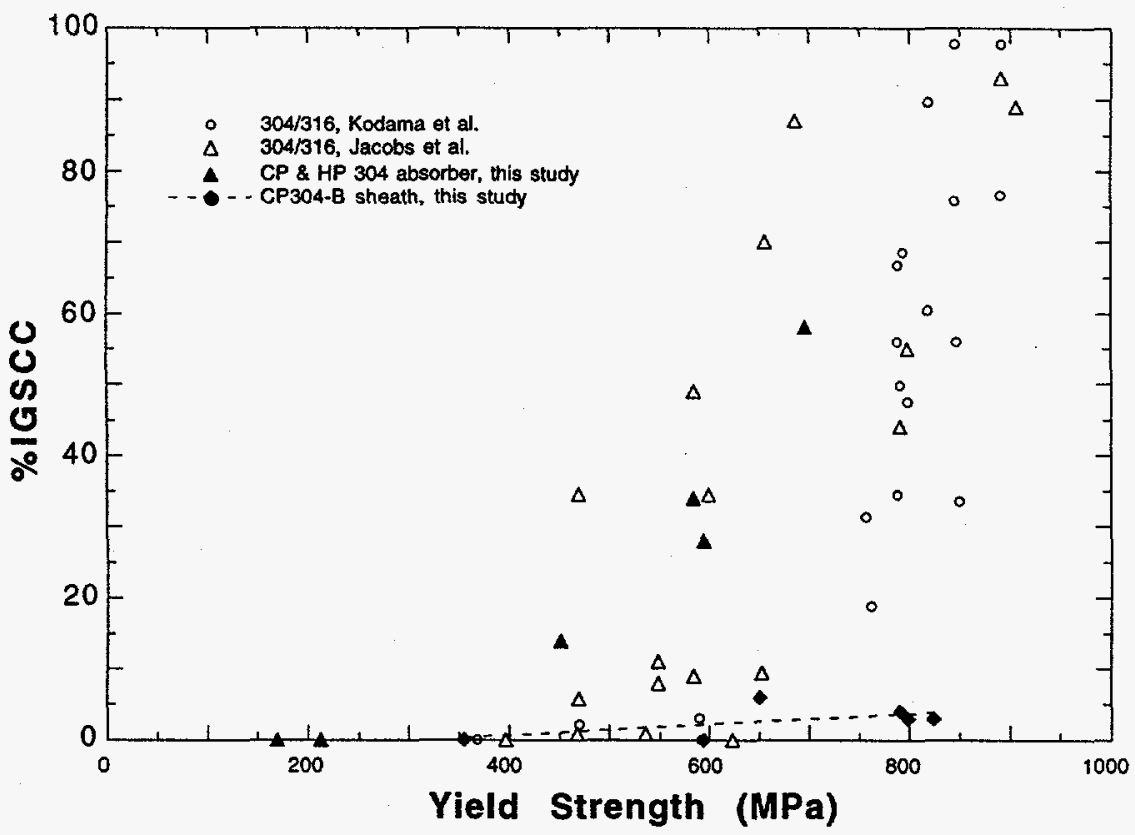

Fig. 3. Percent IGSCC vs. fluence for Type 304 SS and CP 316 SS from SSRT tests at $289^{\circ} \mathrm{C}$ in water.

The rationale for implicating yield strength is that IASCC may be controlled primarily by irradiation hardening of the grain matrix in addition to grain-boundary processes that promote stress corrosion. However, results given in Fig. 3 indicate clearly that although irradiation-induced hardening renders plastic deformation within grains more difficult, a certain grain-boundary weakening process is essential for inducing IGSCC in the irradiated materials in water.

\section{Effect of Dissolved Oxygen in Water}

In Fig. 4, effects of dissolved oxygen (DO) on \%IGSCC vs. fluence are shown for the HP (HP304-A, B, and CD, Table 1) and CP neutron absorber tubes. Susceptibility of the control blade sheath (fabricated from another CP-grade heat) to IGSCC was negligible for all fluence levels; therefore, no tests were conducted to investigate the effect of DO levels other than $\approx 0.3 \mathrm{ppm}$. Percent IGSCC vs. DO (in the range of 0.02 to $32 \mathrm{ppm}$ ) for CP Type 304 SS dry tubes, reported by Indig et al. ${ }^{4}$ and Kodama et al., 5 is also shown in the figure for comparison. Th effects of DO of $>0.01 \mathrm{ppm}$ on the susceptibilities of the CP Type 304 SS neutron absorber and dry tubes appear to be similar.

However, DO dependence of the neutron absorber tubes fabricated from the HP heats appears to be different in several ways from those of the tubes fabricated from the $\mathrm{CP}$ material: for comparable fluence levels, susceptibility of the former materials to IGSCC seems to be less dependent on DO than is the latter material at low oxidation potentials. Furthermore, some degree of susceptibility to IGSCC was observed in the HP materials even at the very low DO of $\approx 0.001 \mathrm{ppm}$. Susceptibility of the HP materials was significantly higher than that of $\mathrm{CP}$ materials regardless of either DO or fluence. A similar trend is also obvious from Fig. 5, in which the effect of ECP on \%IGSCC is shown. In the figure, results obtained for CP 304 SS by Indig et al.4 agree well with those from the present 
investigation, whereas HP tubes exhibit distinct cracking behavior less sensitive to ECP than the CP materials.

\section{Crack Growth Rate}

Approximate intergranular crack growth rate (IGCGR) was estimated from SSRT data by a procedure similar to that of Jenssen and Ljungberg. ${ }^{22}$ In the present study, however, CGR was estimated only for specimens in which through-wall IG cracking had been confirmed by SEM fractography. For such specimens, the depth and time of IG cracking can be determined fairly accurately from the fracture-surface map and load-elongation curve, respectively. The estimated CGRs determined in this way are plotted as a function of ECP in Fig. 6. Also shown in the figure are similar results reported by Jenssen and Ljungberg 22 and CGRs calculated from the SSRT and constant-load test data reported by Kodama et al.5,10 and Katsura et al., 13 respectively.

Results in Fig. 6 indicate that IGCGRs determined from SSRT and constant-load tests on BWR components are similar for similar fluence at high ECP. However, these rates obtained from BWR components are significantly higher than those obtained from the rodshaped specimens of Jenssen and Ljungberg. ${ }^{22}$ Strain rate was significantly different in these tests, ranging from $5 \times 10^{-8} \mathrm{~s}^{-1}$ to $2.5 \times 10^{-7} \mathrm{~s}^{-1}$. It is not clear if CGRs determined from actual reactor components are influenced significantly by the fabrication variables and differences in irradiation conditions. However, test parameters such as stress intensity and strain rate should influence CGR significantly. Most likely, stress intensity was not comparable for the tests examined in Fig. 6. A more accurate comparison would be possible if CGRs were measured under conditions of constant stress intensity.

Although the threshold ECP of $<-140 \mathrm{mV}$ SHE to suppress IASCC in the CP materials in BWR was confirmed to agree well with that reported by Indig et al., 4 the contrasting dependence of susceptibility to intergranular stress corrosion cracking (IGSCC) of the HP and CP materials on water chemistry (DO and ECP) was unexpected.

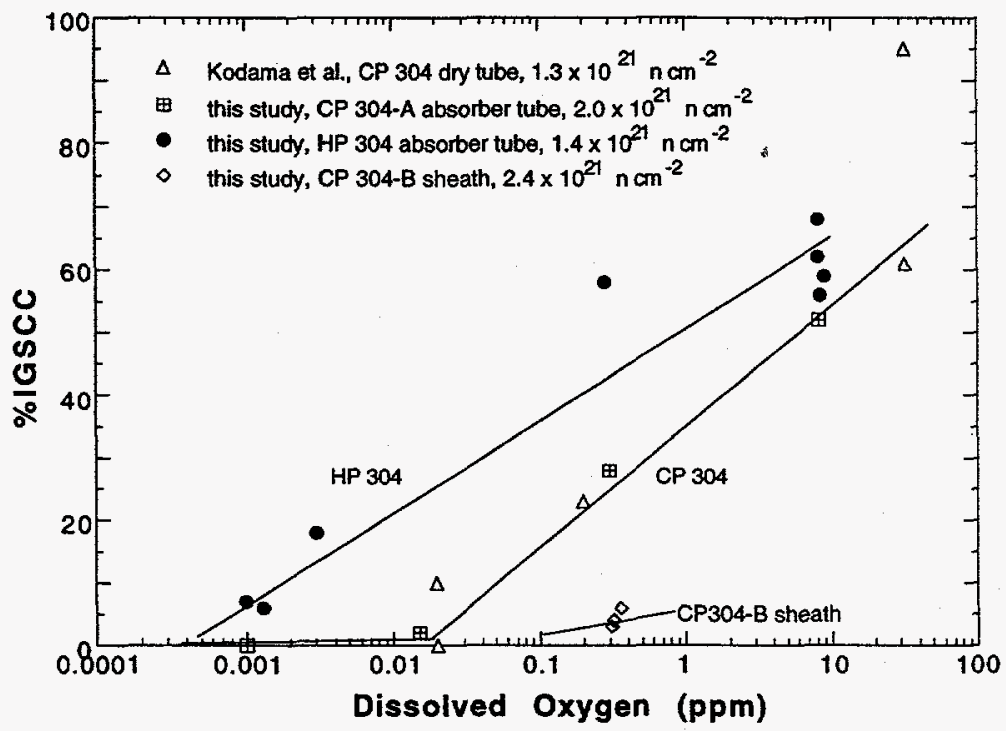

Fig. 4.

Comparison of \%IGSCC us. DO of high-and commercial-purity Type 304 SS neutron absorber tubes and commercialpurity Type 304 SS dry tubes.

\section{Effect of Grain-Boundary Cr Concentration}

For a limited number of heats of austenitic stainless steels, a fairly good correlation is obtained between \%IGSCC and grain-boundary concentration of $\mathrm{Cr}$, e.g., Fig. 7. This indicates the significant role of $\mathrm{Cr}$ depletion on LASCC. Most of the published data similar to those of Fig. 7 were, however, obtained by the FEG-AAEM energy-dispersive spectroscopy (EDS) technique. These data are plotted in Fig. 8 as a function of \%IGSCC, 
together with those obtained by AES in the present investigation. Apparently, the correlation between \%IGSCC and grain-boundary concentration of $\mathrm{Cr}$ in Fig. 8 is not good, and it seems to be difficult to rationalize that grain-boundary $\mathrm{Cr}$ depletion is the only process that causes IASCC.

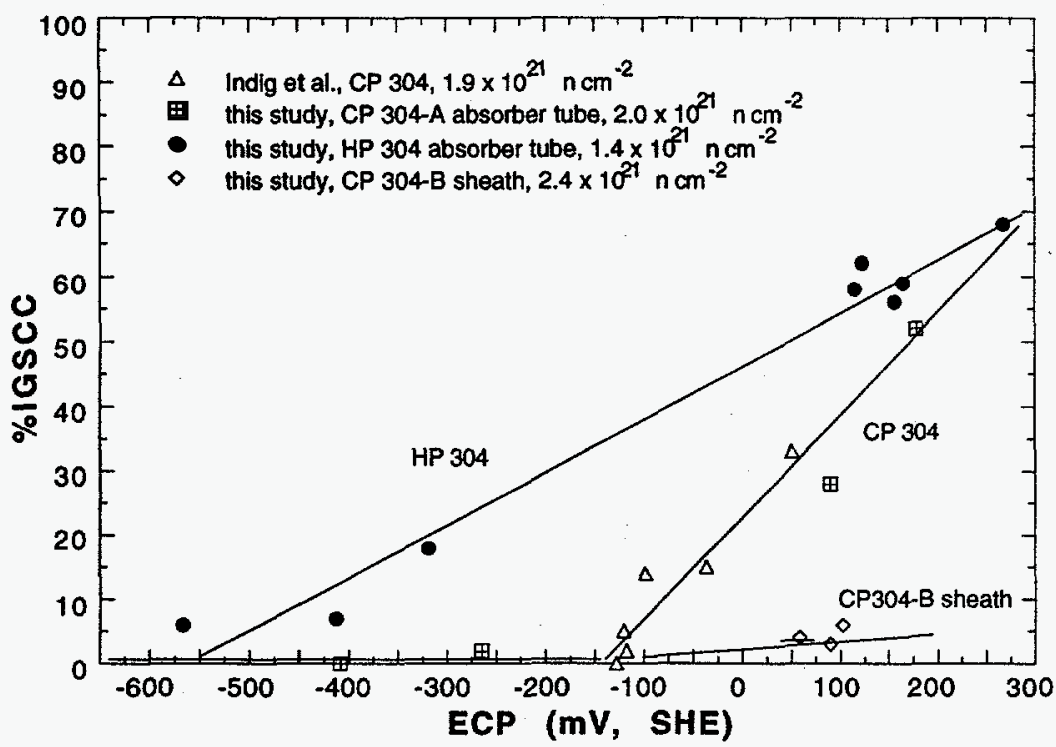

Fig. 5.

Comparison of \%IGSCC vs. ECP of high- and commercial-purity Type 304 SS neutron absorber tubes (this study) and commercialpurity Type 304 SS BWR sheet component. 4

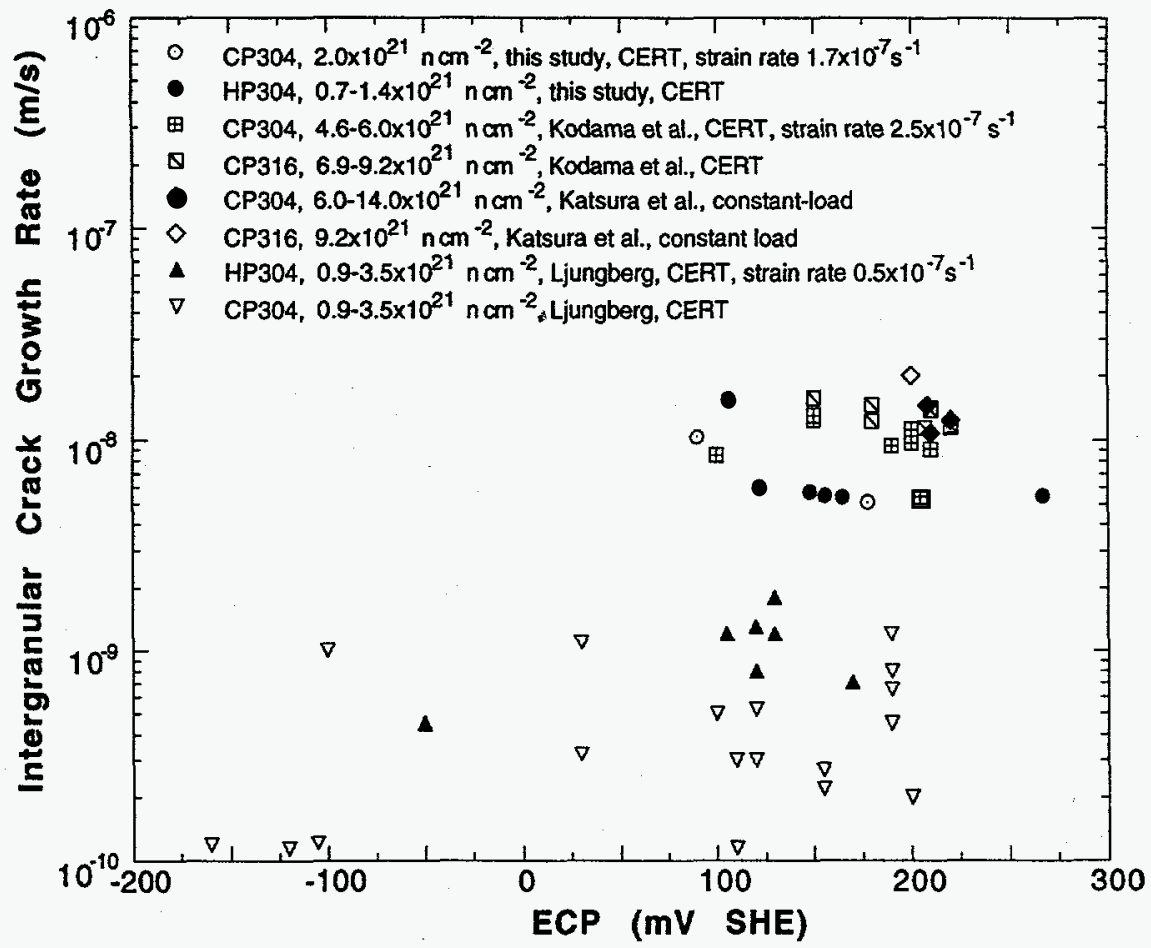

Fig. 6. Intergranular crack growth rate vs. ECP determined from constant-extension SSRT and constant-load test on BWR tube components and rod-tensile specimens irradiated in BWR. 
Determination of accurate grain-boundary concentrations in LWR components is difficult. Only two techniques can provide reasonable means of measurement, i.e., AES depth-profiling and FEG-AAEM energy-dispersive spectroscopy (EDS). Depth-profiling is necessary in AES because $\mathrm{Cr}$ signal is influenced by $\mathrm{O}$ contamination from the high vacumm environment of the Auger electron microscope. ${ }^{7}$ Without proper sputtering and depth profiling, AES tends to produce lower $\mathrm{Cr}$ concentrations at grain boundaries because of the problems associated with the oxygen contamination. FEG-AAEM-EDS has several important limitations: the effects of imperfect grain-boundary alignment (e.g., 1-nm uncertainty produced with $1^{\circ}$ misalignment in $57-\mathrm{nm}$-thick film), effect of large beam size, beam broadening, effect of a $\mathrm{Cr}_{2} \mathrm{O}_{3}$ surface layer, and fluoresced $\mathrm{Cr} \mathrm{X}$-ray. Because of these limitations, FED-STEM technique tends to produce higher $\mathrm{Cr}$ concentrations at grain boundaries, and a great caution must be exercised in interpreting data from presentgeneration FEG-STEM-EDS analysis of LWR components in which meaningful Cr-depletion profile is the profile within $\approx 1 \mathrm{~nm}$ of a grain boundary.

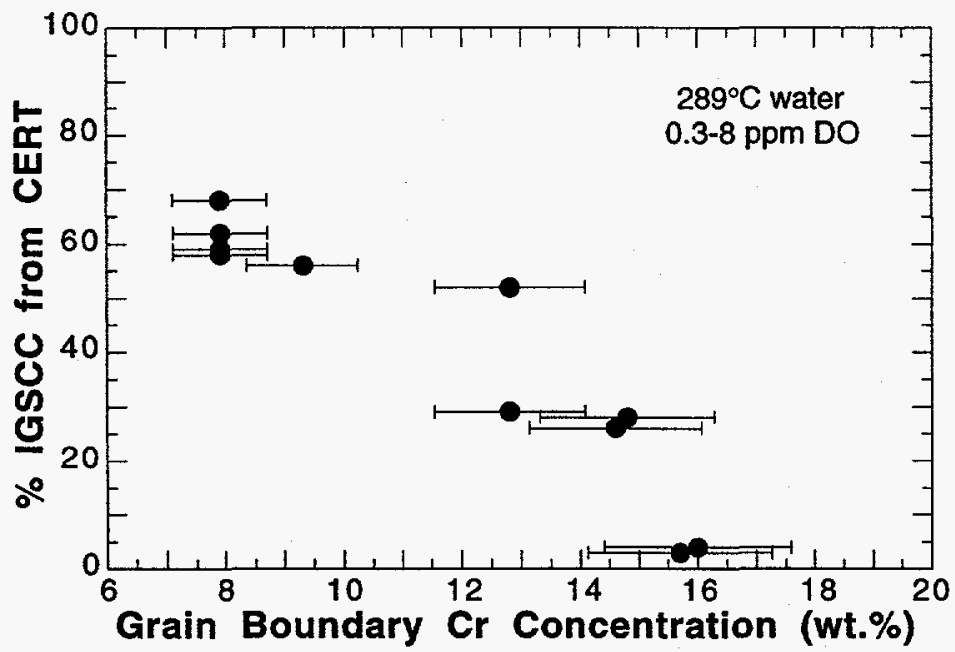

Fig. 7.

Susceptibility to IGSCC vs. grain-boundary $\mathrm{Cr}$ concentration determined by AES for $H P$ and $C P B W R$ components irradiated to $2 \times 10^{21} \mathrm{n} / \mathrm{cm}^{2}$.

Without a proper understanding of the limitations of the techniques and uncertainties of measurement, the exact role of grain-boundary $\mathrm{Cr}$ depletion in IASCC (i.e., primary or secondary role) cannot be convincingly determined at present. Nevertheless, the large variation in percent IGSCC for a similar grain-boundary $\mathrm{Cr}$ content in Fig. 8 appears to suggest that an unidentified process other than $\mathrm{Cr}$ depletion plays an important role. It is also difficult to explain some of the well-known characteristics of IASCC on the basis of a premise that grain-boundary depletion of $\mathrm{Cr}$ plays a primary role. For example, it has been commonly observed that heats of Type 304,316 , and 348 SS of virtually identical chemical composition exhibit very different susceptibilities to IASCC, which cannot be explained on the basis of a mechanism that grain-boundary $\mathrm{Cr}$ depletion is the primary process responsible for IASCC. It is also difficult to explain the significant cracking susceptibility observed after irradiation at temperatures as low as $\approx 50^{\circ} \mathrm{C} .14$

\section{Effect of Nonequilibrium Segregation of Cr during Fabrication}

One factor that complicates the susceptibility of a heat of a given composition to IASCC appears to be the equilibrium and nonequilibrium segregation of alloying and impurity elements to grain boundaries by thermal process during component fabrication. Nonequilibrium grain-boundary segregation of $\mathrm{Cr}$ and $\mathrm{Mo}$ and depletion of $\mathrm{Fe}$ during fabrication appears to be common. An example is shown in Fig. 9, in which grain-boundary profiles of $\mathrm{Cr}$ and $\mathrm{Ni}$ were obtained on a nonirradiated heat of Type 304 SS by the Vacuum Generator HB603 FEG-AAEM. This type of nonequilibrium segregation, which will be influenced by component thickness and cooling rate after solution treatment, appears at least in part to contribute to heat-to-heat variation in IASCC susceptibility of stainless steels of similar chemical composition. 


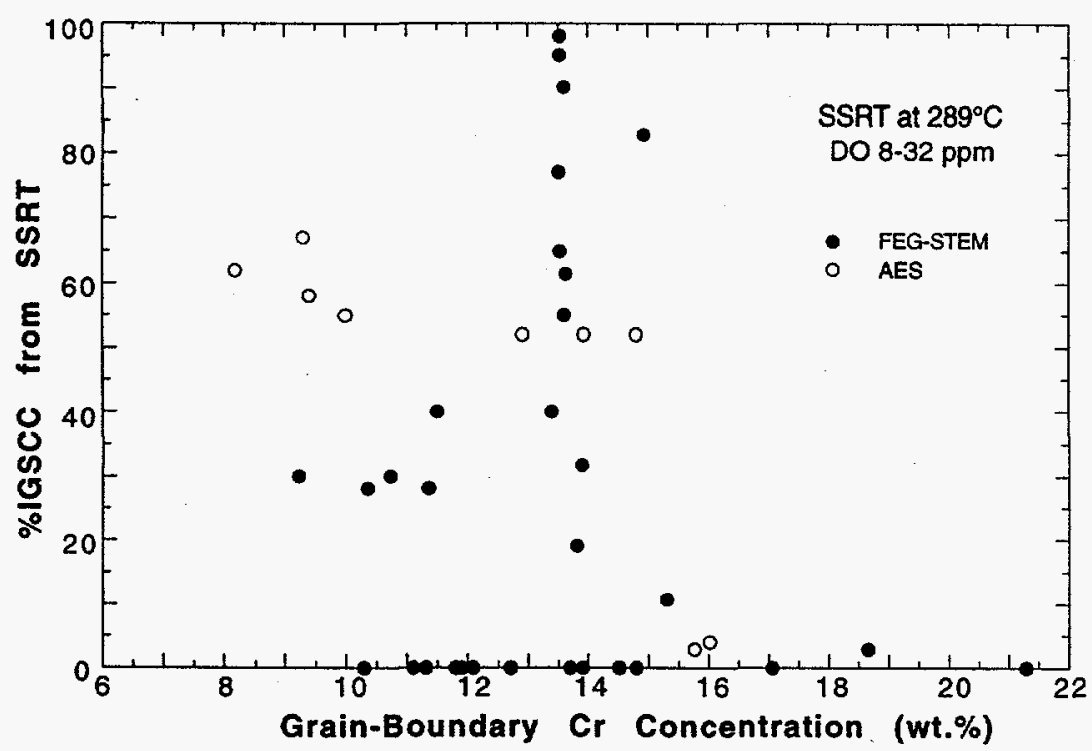

Fig. 8.

Percent IGSCC us. minimum grainboundary $\mathbf{C r}$ content determined from SSRT tests and AES and FEG-AAEM analyses of $L W R$ components.

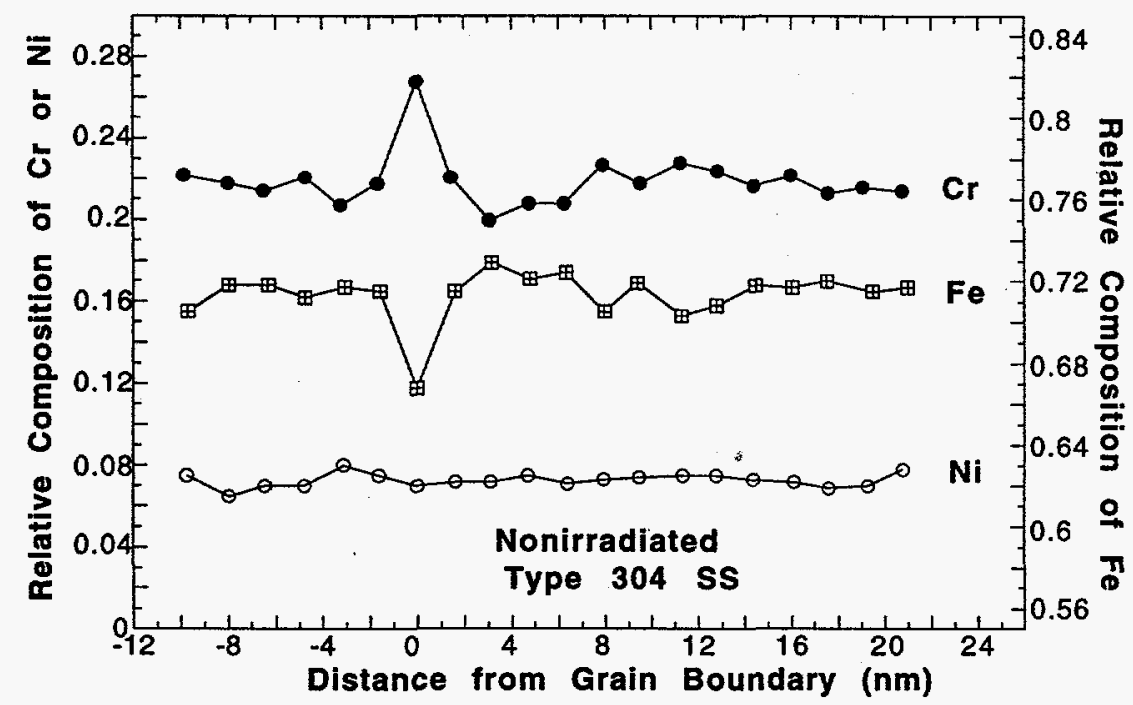

Fig. 9.

Grain-boundary profiles of $\mathrm{Cr}$, $\mathrm{Ni}$, and $\mathrm{Fe}$ in nonirradiated rod specimen fabricated from Type 304 SS.

The thermally segregated $\mathrm{Cr}$ profile induced during fabrication such as that shown in Fig. 9 is altered by irradiation-induced inverse Kirkendall process during service. As a result, characteristic "double-peak" $\mathrm{Cr}$ profiles are observed near the grain boundaries. Examples of such profiles are shown in Fig. 10, which were obtained by AES. The AES profiles show only single Cr peak, because AES data can only be obtained from one side of a grain boundary. The figure also shows that width of the four profiles of the thermally segregated $\mathrm{Cr}$ (three determined by AES and one determined by FEG-AAEM) is similar, i.e., 3-4 $\mathrm{nm}$ from the grain boundary.

\section{Effect of Nickel}

For similar fluence level, heats of Type 304 SS with higher Ni concentration on grain boundaries appear to exhibit relatively lower susceptibility to IASCC (Fig. 11). This is qualitatively consistent with similar observation reported by Cookson et al. 9 It seems that lower Ni concentration tends to increase metastability of grain boundaries in austenitic stainless steels. However, for a given component under irradiation, any beneficial effect of 
increasing concentration of $\mathrm{Ni}$ on grain boundaries will be more than offset by other deleterious effects associated with or induced by increased irradiation damage.
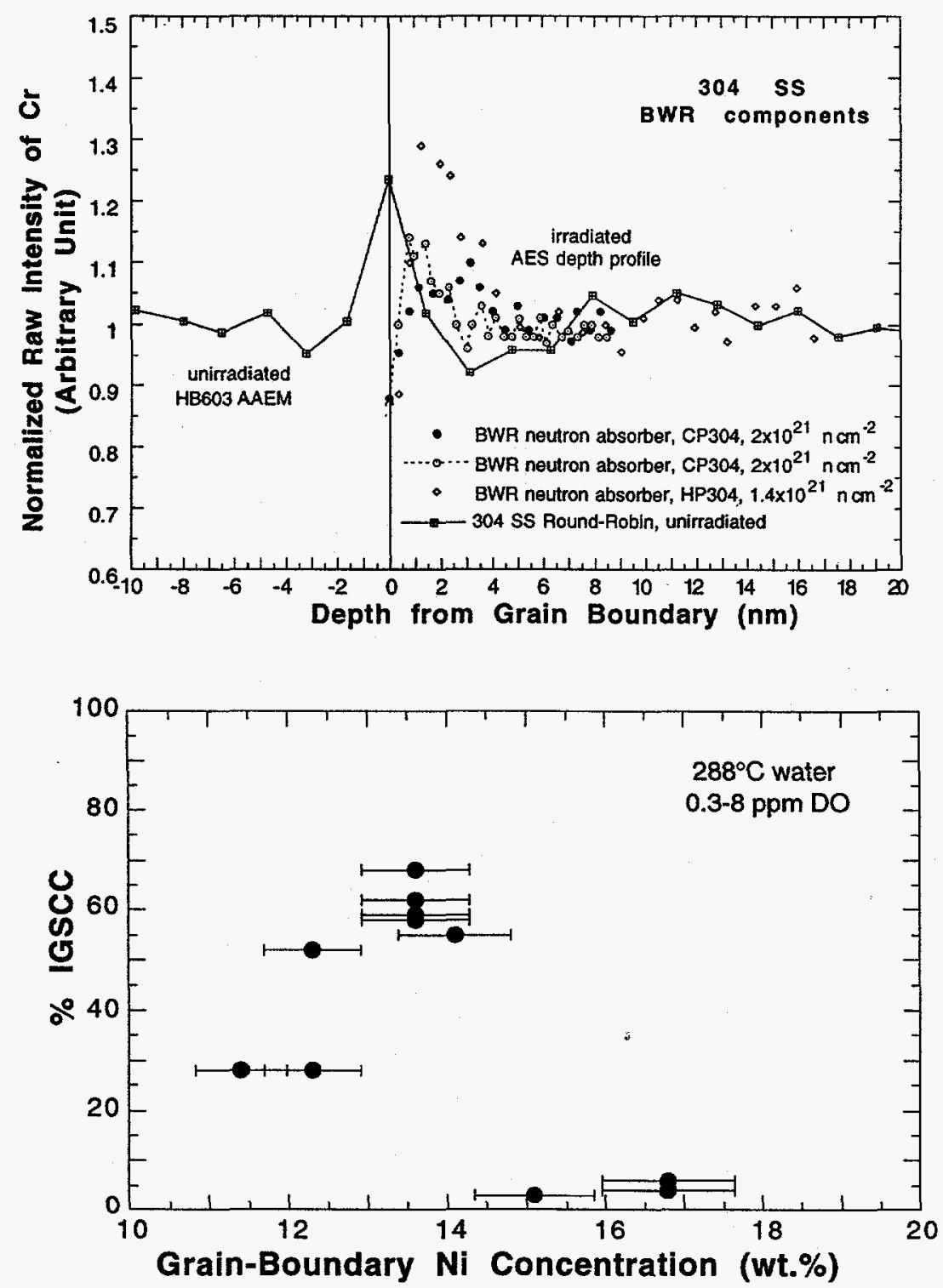

Fig. 10.

Grain-boundary $\mathrm{Cr}$ depletion profiles in nonirradiated Type 304 SS round-robin specimen measured by FEG-AAEM and irradiated BWR neutronabsorber tubes measured by AES. Note initial $\mathrm{Cr}$ segregation by nonequilibrium thermal process and subsequent $\mathrm{Cr}$ depletion during irradiation.

Fig. 11.

Percent IGSCC vs. grainboundary concentration of $\mathrm{Ni}$ measured on grain boundaries in the BWR components that were irradiated to 1.4 to $2.4 x$ $10^{21} \mathrm{n} \mathrm{cm}^{-2}$.

\section{Effects of Silicon and Phosphorus}

In Figs. 12(A) and (B), percent IGSCC from SSRT tests has been plotted as a function of grain-boundary concentration of $\mathrm{Si}$ and $\mathrm{P}$, respectively. Depth of IG-fracture penetration, produced in hydrogen-charged specimens in vacuo at room temperature, has also been plotted. No good correlation was observed between the susceptibility to $\mathrm{H}$ induced IG cracking and grain-boundary concentration of Si or P. Percent IGSCC in water decreased monotonically with increased grain-boundary concentrations of $\mathrm{Si}$ and $\mathrm{P}$. It is, therefore, difficult to explain the significant IGSCC in the HP absorber tube specimens or the negligible SCC susceptibility of the CP sheath specimens on the basis of grain-boundary segregation of $\mathrm{Si}$ or $\mathrm{P}$. The present results show that radiation-induced grain boundary segregation of $\mathrm{Si}$ or $\mathrm{P}$ is not the mechanism of IASCC of Type $304 \mathrm{SS}$, as has been speculated previously. Furthermore, the results also imply that the low content of Si or P is not the primary factor associated with the better resistance of some of the high-purity 
heats of Type 304,316 , and 348 SS. Results that lend support to this have been also reported by several investigators. $6,9,11,14,19 \mathrm{Si}$ in fact seems to help suppress IASCC, although a similar role for $\mathrm{P}$ is less convincing. 12.19

\section{Effect of Sulfur}

No evidence of grain-boundary segregation of $S$ was observed in the present analysis. However, the effect of $S$ on IASCC is believed to be complicated because the $S$ is strongly trapped by sulfides that precipitate commonly in stainless steels. MnS and other forms of sulfides also are known to be dissolved in LWR water. Therefore, a good correlation between \%IGSCC and grain-boundary S concentration cannot be established even if S plays a deleterious role in IASCC.
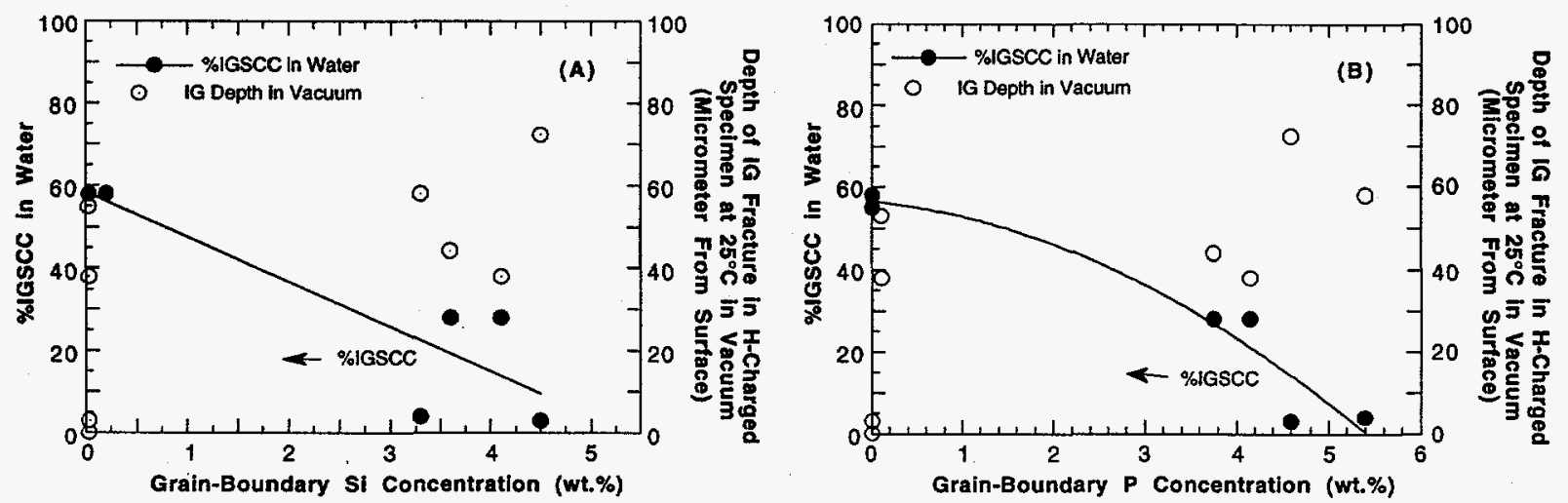

Fig. 12. Percent IGSCC in water and depth of intergranular fracture penetration in hydrogen-charged specimens, fractured at room temperature in vacuo, as a function of grain-boundary segregation of Si $(A)$ and $P(B)$. Fluence level of specimens was $\approx 2 \times 10^{21} \mathrm{n} / \mathrm{cm}^{2}$.

\section{Effect of Boron}

Boron-10 ( $\approx 20 \%$ in natural boron) transmutes at low fluences to $\mathrm{Li}$ by thermal neutrons (cross section $\approx 3840$ barn). A previous report showed that \%IGSCC correlates well with the intensities of Auger electrons that give rise to a characteristic peak at $\approx 58 \mathrm{eV}$ that has been identified as the secondary peaks of $\mathrm{Ni}$ and $\mathrm{Li} .{ }^{8}$ This seems to indicate that higher concentrations $\mathrm{Li}$, and hence $\mathrm{B}$, are beneficial in suppressing IASCC. Consistent with this, the high-boron heats of Type 304 and 316 SS investigated by Jenssen and Ljungberg appear to show lower susceptibility to IASCC than do the lower-boron heats. 22 Quantitative determination of $\mathrm{Li}$ in stainless steels by AES technique is very difficult, however, because of the secondary peaks of $\mathrm{Ni}$ and $\mathrm{Fe}$; thus, further investigation into the role of $\mathrm{Li}$ and $\mathrm{B}$ is necessary. The beneficial role of $B$ in reducing SCC in nonirradiated austenitic stainless steels is well known.

\section{Effect of Nitrogen}

Indications of the deleterious effect of grain-boundary segregation of $\mathrm{N}$ have been observed for the present BWR components (Fig. 13). Similar reports suggests that a higher concentration of $\mathrm{N}$ is deleterious, at least for BWR conditions. $3,12,19,22$ Indication of deleterious role of $\mathrm{N}$ seems to be more convincing for Type 304L and 316L SSs containing low C (e.g., < $240 \mathrm{wppm}$ ) and irradiated in BWR or in test reactors at $240-300^{\circ} \mathrm{C}$. This is shown in Fig. 14. Kasahara et al.12 reported that higher $\mathrm{N}$ in Type $316 \mathrm{~L}$ increased the susceptibility to IASCC, indicating that Type $316 \mathrm{LN}$ is a susceptible material. This observation is consistent with the behavior of $316 \mathrm{NG}$ reported by Jacobs et al. ${ }^{3}$ and Jenssen and Ljungberg. 22 In contrast to this, 316NG irradiated at $\approx 50^{\circ} \mathrm{C}$ has been reported to be resistant to intergranular failure at $\approx 288^{\circ} \mathrm{C}$ in water containing $32 \mathrm{ppm} \mathrm{DO} .14$ The 
deleterious effect of $\mathrm{N}$ could be associated with slow transmutation of $\mathrm{N}$ by thermal neutrons to hydrogen on grain boundaries.

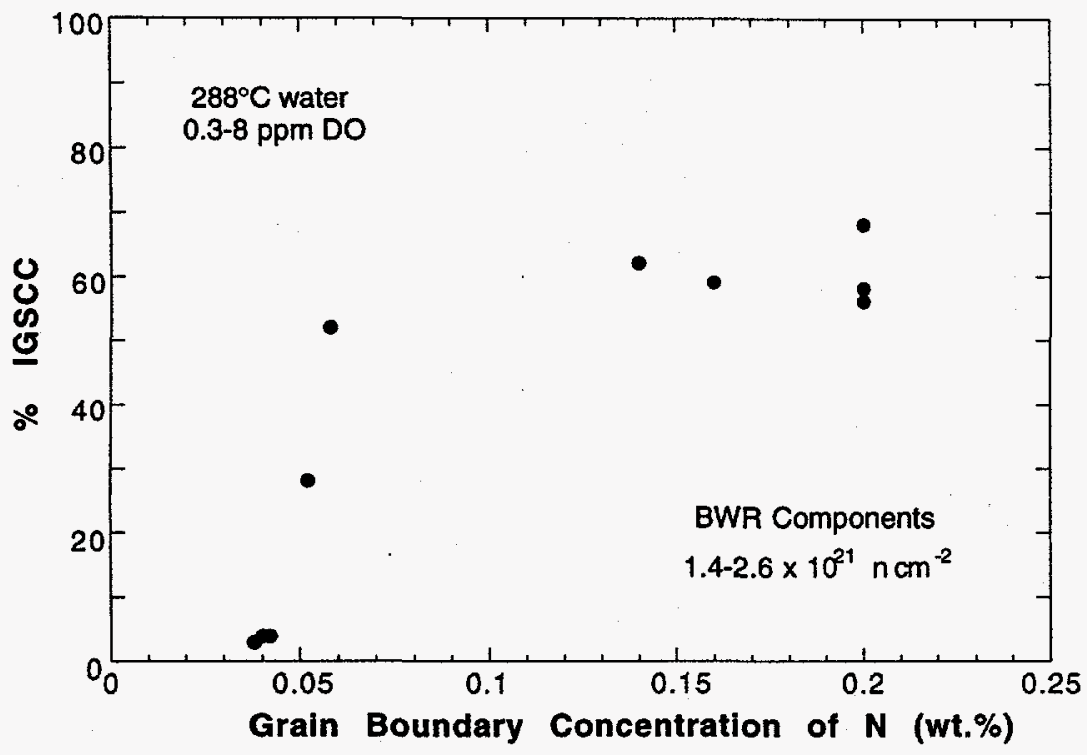

Fig. 13.

Percent IGSCC vs. grain-boundary concentration of $N$ in $B W R$ components irradiated to 1.4 to 2.4 $\times 10^{21} \mathrm{n} \mathrm{cm}^{-2}$.

\section{Effect of Vanadium}

Vanadium is widely used in stainless steels as a strengthening element and is found in most commercial heats, probably as additives in the beginning of the iron and steelmaking processes or from recycled scrap. Susceptibility to IASCC appears to increase with increased grain-boundary concentration of V (see Fig. 15). The apparently deleterious effect of $\mathrm{V}$ is, however, not understood at this time. One possible explanation is the increased yield strength of grain matrix in association with increased $\mathrm{V}$ content. Vanadium is also known to form vanadates and other complex compounds readily, some of them soluble in water. ${ }^{28}$ However, this is only a speculation, and further invetigation is necessary.

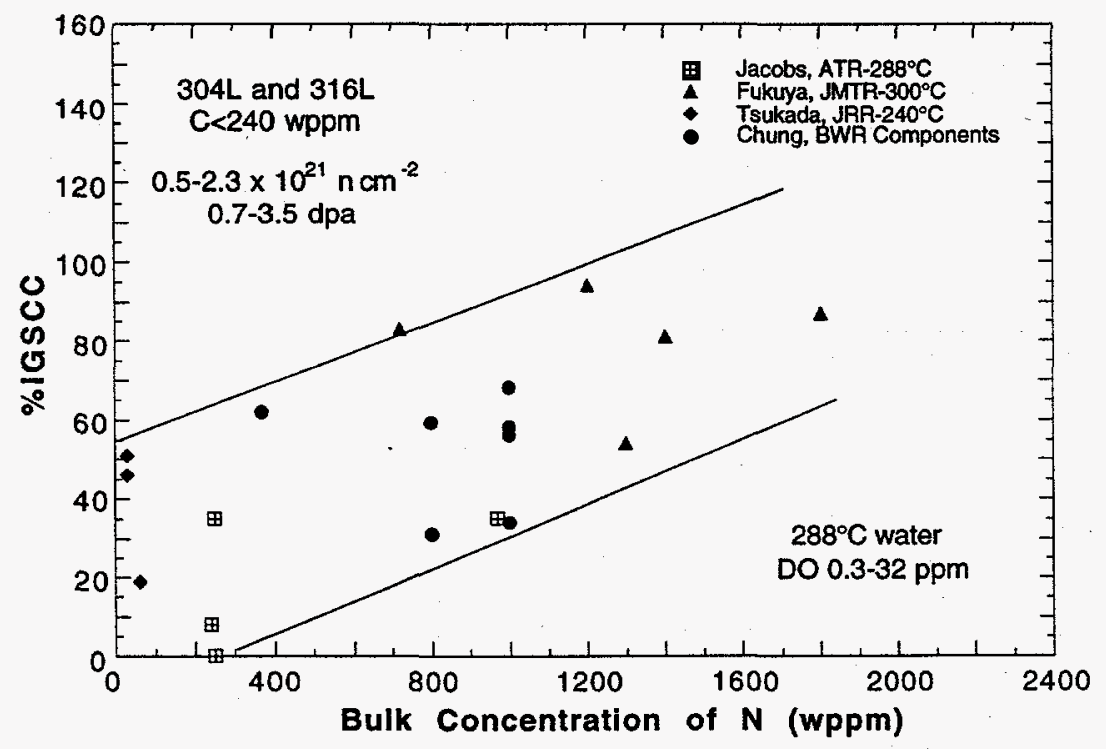

Fig. 14.

Percent IGSCC vs. bulk $N$ content of Type $304 L$ and $316 L$ SSs $(C<240$ wppm) irradiated in $B W R$ and in test reactors at $240-300^{\circ} \mathrm{C}$. 


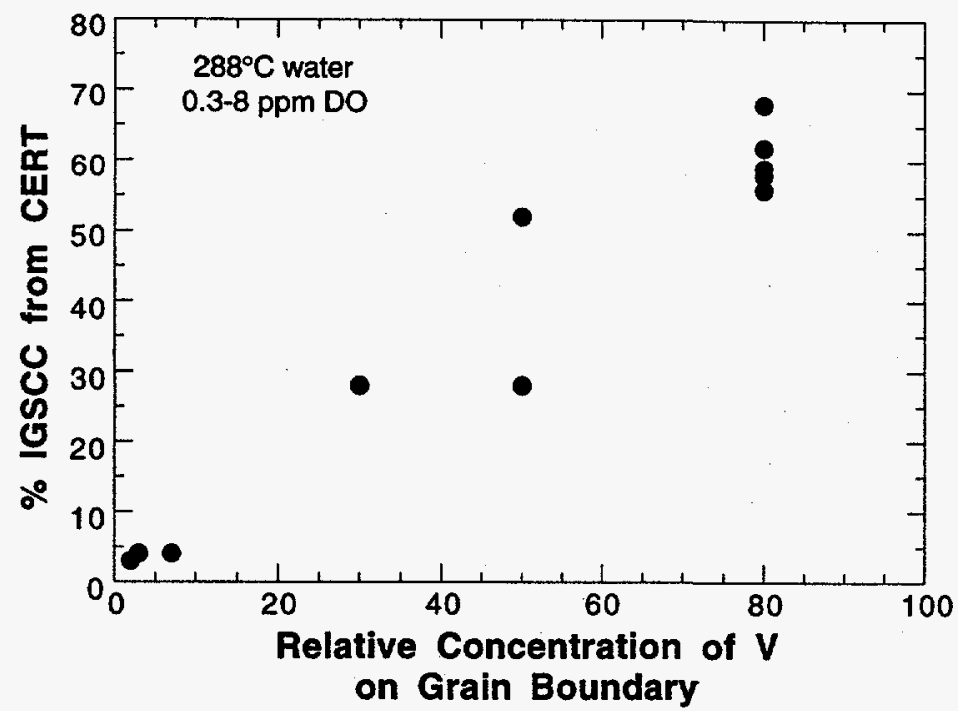

Fig. 15.

Percent IGSCC us. grainboundary concentration of $V$ in BWR components irradiated to 1.4 to $2.4 x$ $10^{21} \mathrm{n} \mathrm{cm}^{-2}$.

\section{Effect of Carbon}

Carbon significantly increases the yield strength of irradiated stainless steels. Higher carbon content seems to suppress the susceptibility to intergranular cracking of irradiated materials (Fig. 16) but increases susceptibility to transgranular stress corrosion cracking. Hence, Type 304L stainless steels appear to be generally more susceptible to IASCC. This behavior has been observed consistently by other investigators.6,9,12,14,19

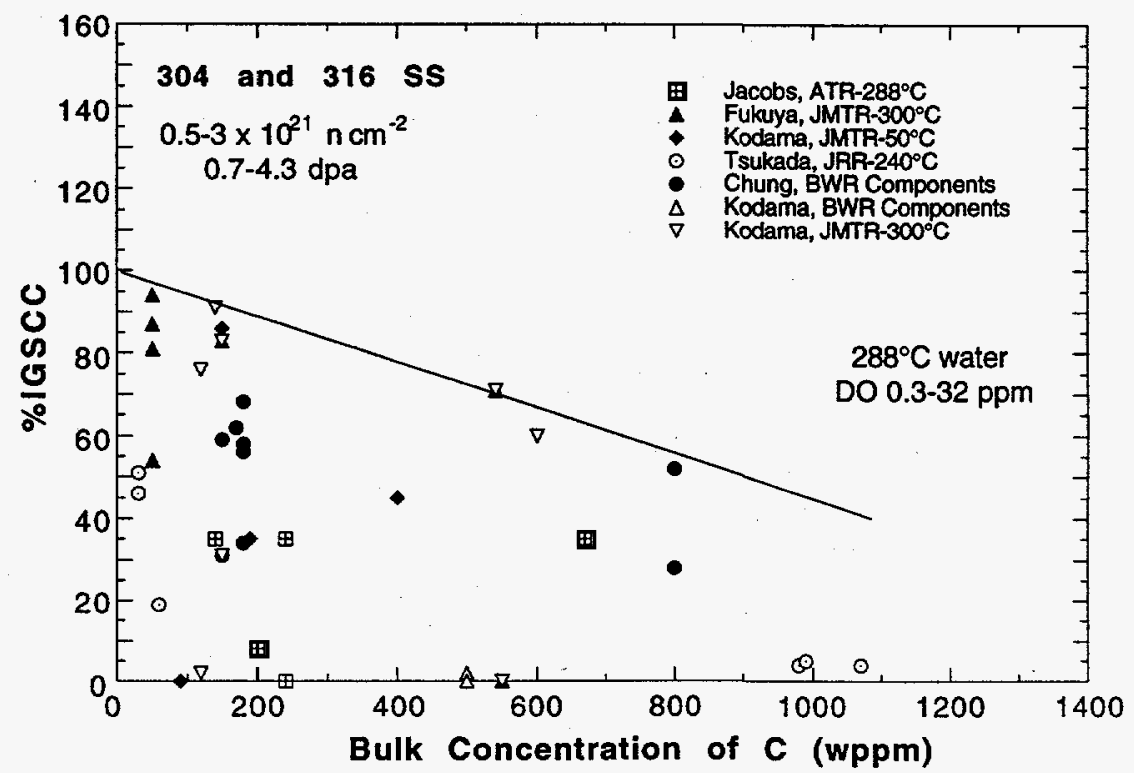

Fig. 16 .

Percent IGSCC us. bulk concentration of C of Type 304 and 316 SSs irradiated to 0.5 to $3.0 \times 10^{21}$ $n \mathrm{~cm}^{-2}$ in $B W R$ and in test reactors at $240-300^{\circ} \mathrm{C}$.

\section{Effect of Fluorine}

A preliminary finding in Ref. 29 indicated that a relatively higher level of $\mathrm{F}$ on grain boundaries in HP absorber tubes is associated with higher susceptibilities of the material to IASCC. Inadvertent contamination of reactor components by fluorine is associated with one of three procedures: (1) pickling of machined and finished components in a solution containing $\mathrm{HF}$, in the case of tubular components; (2) use of $\mathrm{F}$-containing weld flux (CaF or $\left.3 \mathrm{NaF} \cdot \mathrm{AlF}_{3}\right)$ in the submerged-arc and shielded-metal-arc welding that are commonly employed to weld large field components; and (3) use of neutral flux fluorspar $\left(\approx 75 \% \mathrm{CaF}_{2}\right)$ in iron- and steelmaking. 
The effect of fluoride ions dissolved in water on the stress corrosion cracking of nonirradiated sensitized stainless steel has been reported first by Ward et al.30 In that study, $F$ ions as low as $\approx 1 \mathrm{ppm}$ in water produced intergranular cracking to varying degrees in sensitized Type 304, 316, and 348 SS. Besides thermal sensitization, at least one of the following conditions is prerequisite for intergranular attack in the nonirradiated materials: (1) tensile stress (applied or residual), (2) cold work, (3) a crevice, or (4) visible oxide film. Ward et al. 30 also observed accelerated IGSCC of nonirradiated thermally sensitized bend specimens or weldments of CP-grade Type 304 SS that were contaminated with F. Similar to this observation, the IASCC-resistant CP sheath in the present study was characterized by negligible grain-boundary $\mathrm{Cr}$ depletion and absence of $\mathrm{F}$. On the other hand, the IASCC-susceptible HP absorber tubes were characterized by significant grainboundary $\mathrm{Cr}$ depletion and relatively high F levels. Similar to the dependence of IASCC of the HP neutron absorber tubes to DO and ECP observed in the present investigation, Ward et al. reported also that F-assisted IGSCC was less sensitive to DO than was classical IGSCC of thermally sensitized $F$-free specimens.

Halide ions, in particular $\mathrm{Cl}$ and $\mathrm{F}$, are well known to play catalytic roles in accelerating aqueous corrosion of steels in water. 31 However, a mechanistic understanding of $\mathrm{F}-$ assisted intergranular cracking and the strong influence of grain-boundary $\mathrm{Cr}$ depletion (via either thermal sensitization or irradiation-induced process) remains unexplained. Deleterious effects of fluorine on IGSCC in nonirradiated materials of stainless steel,30-37 Inconel 182,37 and brass 38 has been well established from reports by many investigators, some on the effect of fluorine in water, $30-38$ and others on the effect of material contamination by fluorine. $30,34,35$ In the latter type of investigations, the primary sources of fluorine contamination were weld flux and weld fumes that are associated with submerged-arc and shielded-metal-arc welding.

The catalytic role of halide impurities in accelerating aqueous corrosion of $\mathrm{Fe}$ and $\mathrm{Fe}-$ based alloys is known to be strongly influenced by the concentration of $\mathrm{Cr}$ ions in water. 31 The corrosion acceleration has been attributed to the orders-of-magnitude faster rate of formation of a ligand complex between Fe-halide (i.e., halide anion chemisorbed on $\mathrm{Fe}$ adsorbent) and $\mathrm{H}_{2} \mathrm{O}$ molecules than the rate of formation of a similar ligand complex between halide-free $\mathrm{Fe}$ atom and $\mathrm{H}_{2} \mathrm{O}$ molecules. A similar effect can be postulated for relative reaction rates to form $\mathrm{F}$-containing and $\mathrm{F}$-free ligand complexes of $\mathrm{FeF}\left(\mathrm{H}_{2} \mathrm{O}\right)_{5}$ and $\mathrm{Fe}\left(\mathrm{H}_{2} \mathrm{O}\right)_{6}$, respectively. A halide atom is released from the labile ligand complex le.g., $\mathrm{FeF}\left(\mathrm{H}_{2} \mathrm{O}_{5}\right.$ l dissolved in water when $\mathrm{H}_{2} \mathrm{O}$ replaces the halide atom in the complex, thus leading to a classical catalytic role by the halides. However, this reaction chain is broken when the concentration of $\mathrm{Cr}$ ions in water is high (e.g., in the crack tip at grain boundaries of relatively insignificant $\mathrm{Cr}$ depletion), because the $\mathrm{Cr}$-halide- $\mathrm{H}_{2} \mathrm{O}$ ligand complex [e.g., $\mathrm{CrF}\left(\mathrm{H}_{2} \mathrm{O}\right)_{5}$ ] is formed rapidly but remains inert in water, thereby preventing a catalytic role of the halide atoms (e.g., F atoms). According to this model, key factors that influence susceptibility to IASCC will be (1) concentration of free (i.e., not trapped by stable precipitates or compounds) halide atoms (e.g., F) available on grain boundaries, (2) concentration of $\mathrm{Cr}$ ions in the crack tip, and (3) lability of the $\mathrm{FeF}_{\mathrm{x}}\left(\mathrm{H}_{2} \mathrm{O}\right)_{y}$ complex under irradiation in LWR water.

The above model seems to be consistent with not only the behavior of HP-grade neutron-absorber tubes (high susceptibility) and CP-grade control blade sheath (negligible susceptibility) observed in this work, but also with the increased susceptibility to IGSCC of F-contaminated welds of either nonirradiated or irradiated Type 304 SS. The model also predicts that in the absence of an appreciable concentration of $\mathrm{Cr}$ ions in water (at very low ECP), a low concentration of $F$ in steels can sustain the catalytic role in the stagnant environment of the slowly advancing crack tip. Fractographic examination of the cracked HP absorber tubes by stereo SEM revealed that rugged fracture surfaces have a depth as great as $\approx 20$ grains in some regions in the direction perpendicular to the crack propagation. At such a rugged crack tip in which surface-to-volume ratio (of water) is very high, it is more likely that $\mathrm{F}$ ions in water will exist in concentrations sufficiently high to sustain the catalytic reaction. 


\section{AES Analysis of Fluorine in Irradiated Components}

Fluorine analysis by AES was conducted on BWR-irradiated components fabricated from the HP- and CP-grade Type 304 SS listed in Table 1. Also included in the analysis were expanding-mandrel tube specimens fabricated from HP- (Heat $348 \mathrm{~b}$, resistant to failure) and CP-grade heats (Heat 348a, susceptible to failure) of Type 348 SS and irradiated in a BWR to test resistance to IASCC. 11 Preliminary results of AES analysis were also obtained on a Type 304 SS weld specimen (composition unknown) that was sectioned from an irradiated field component.

The AES signals of $F$ in SS can be easily overlooked because the primary $\mathrm{dN}(\mathrm{E}) / \mathrm{dE}$ peak at $\approx 650 \mathrm{eV}$ is hidden behind the strong $\mathrm{Fe}$ peak at $\approx 651 \mathrm{eV}$. However, $\mathrm{F}$ gives rise to the relatively weak secondary peak at $\approx 625 \mathrm{eV}$, which is characteristic to $\mathrm{F}$. At the same time, the peak height at $\approx 650 \mathrm{eV}(\mathrm{F}$ plus $\mathrm{Fe}$ ) should increase proportionately with increased peak height at $\approx 625 \mathrm{eV}(\mathrm{F})$. To analyze these characteristics more quantitatively, nonirradiated standard samples of $\mathrm{FeF}_{2}$ and pure $\mathrm{Fe}$ were examined to obtain standard AES spectra.

In Fig. 17, the $d N(E) / d E$ spectra of Auger electrons, obtained from an unirradiated standard of $\mathrm{FeF}_{2}$ compound (A) and Type 304 SS weld (B), respectively, are shown for comparison. Fluorine in stainless steels could not be detected from the integral-energy spectra. However, in the derivative-energy spectra $\mathrm{dN}(\mathrm{E}) / \mathrm{dE}, \mathrm{F}$ gives rise to a weak secondary peak at $\approx 625 \mathrm{eV}$. Therefore, for increasing $\mathrm{F}$ content in $\mathrm{Fe}$, the peak height at $\approx 625 \mathrm{eV}$ ( $\mathrm{F}$ only) should be linearly proportional to the peak height at $\approx 651 \mathrm{eV}$ (Fe plus F). The data in Fig. 18 were obtained from Type 304 SS neutron absorber tubes, a control blade sheath, and Type 348 SS expanding-mandrel tubes, and they are compared with those from the irradiated Type $304 \mathrm{SS}$ weld and the $\mathrm{FeF}_{2}$ standard. As expected, the peak height at $\approx 650 \mathrm{eV}$ ( $\mathrm{Fe}$ plus $\mathrm{F}$ ) increased linearly with increasing peak height at $\approx 625 \mathrm{eV}$ in a manner consistent with the standard spectra obtained from the unirradiated $\mathrm{FeF}_{2} .{ }^{29}$ This provides a positive identification of the $\approx 625 \mathrm{eV}$ peak as being indeed the secondary peak of $\mathrm{F}$ in the BWR components.

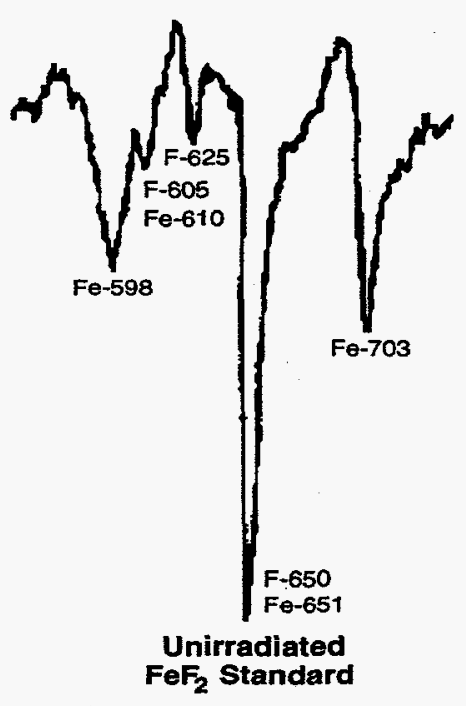

(A) Unirradiated FeF2

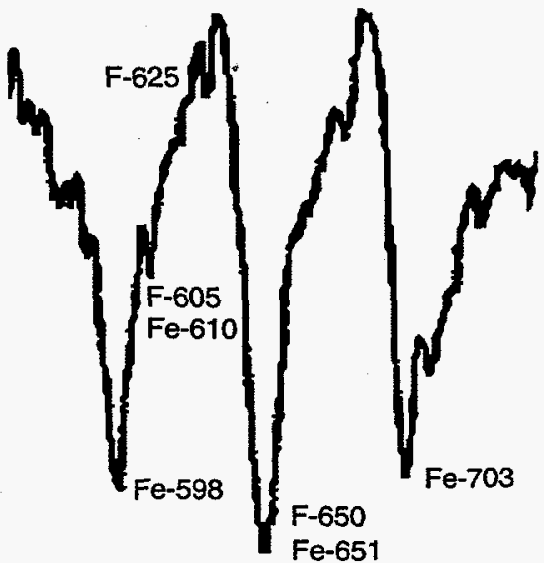

Type 304 SS Irradiated BWR Component

(B) Irradiated 304 SS Weld
Fig. 17

$d N(E) / d E$ spectra from unirradiated standard $\mathrm{FeF}_{2}(\mathrm{~A})$ and irradiated Type 304 SS weld of $B W R$ component (B).

The results given in Fig. 18 indicate that relative $\mathrm{F}$ content in the weld specimen is significantly higher than those in the other solution-annealed BWR components. The figure also indicates that $F$ contents in precipitates and grain boundaries are relatively higher than those in the grain matrices of (unwelded) base metals. Fluorine 625-eV signals from most grain-matrix spots were comparable to background noise or too low to identify 
unambiguously; therefore, only those grain-matrix signals distinctively higher than noise level were plotted in Fig. 18.

Fluorine 625-eV signals from several types of precipitates contained in different heats of SS are shown in Fig. 18, i.e., MnS- and (Ca,Mn)S-type sulfides, spinel-type $\left(\mathrm{FeCr}_{2} \mathrm{O}_{4}\right)$ oxides, and carbides. Formation of Ca-rich sulfides in Heat $348 \mathrm{a}$ is believed to be associated with use of a $\mathrm{CaAl}$ alloy as a deoxidizer in making the steel, because a relatively high level of $\mathrm{Al}$ was also detected in the specimen. The $\mathrm{F}$ signals from sulfides and oxides are significantly higher than those from ductile fracture surfaces (grain matrices). However, $F$ enrichment in carbides seems to be negligible. Because these precipitates are typically formed during fabrication, it is likely that $\mathrm{F}$ enrichment in the sulfides and oxides also occurred by thermal process.

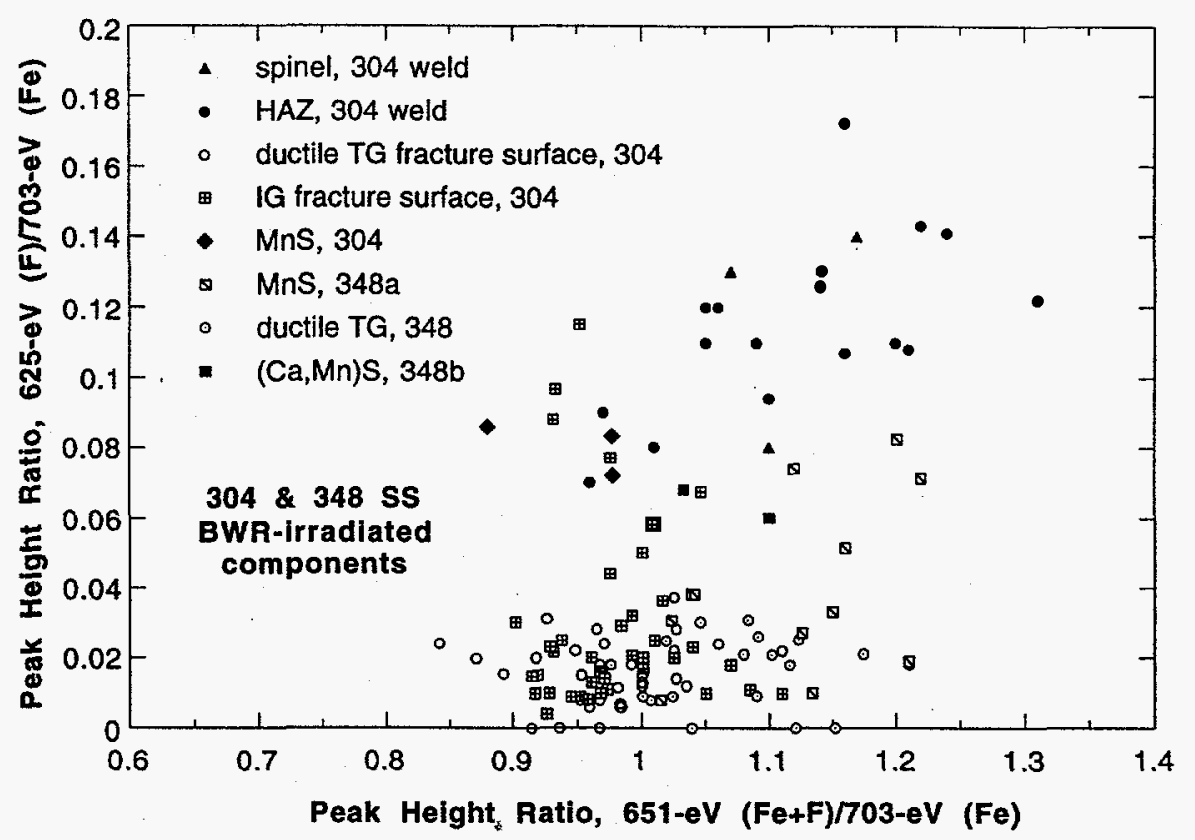

Fig. 18. Relative intensities of Auger electrons of $F$ at $\approx 625$ $\mathrm{eV}$ and $\mathrm{F}$ plus $\mathrm{Fe}$ at $\approx 651 \mathrm{eV}$ from ductile and $\mathrm{IG}$ fracture surfaces and precipitates contained irradiated base metal and weld.

The higher $\mathrm{F}$ levels in precipitates and on grain boundaries appear to be consistent with the very low solubility of $F$ in SSs, because to reduce the total free energy of the system, $F$ will segregate by thermal processes to local sites such as matrix-precipitate interfaces, grain boundaries, and stacking faults. In addition to thermal segregation, irradiation-induced segregation cannot be ruled out. In Fig. 19, the average of the relative level of $\mathrm{F}$ on grain boundaries of several specimens was plotted as a function of percent IGSCC of the heats determined from SSRT tests at a DO level of $\approx 0.3 \mathrm{ppm}$. The figure indicates that higher F on grain boundaries is conducive to higher susceptibility to IASCC.

\section{SSRT Test of Fluorine-Contaminated Irradiated Stainless Steels}

SSRT tests on CP and HP BWR neutron absorber tubes were conducted to determine more directly the effect of fluorine contamination on IGSCC of irradiated steels. $29 \mathrm{CP}$ absorber specimens were tested after soaking in a solution of $3 \mathrm{HF}-15 \mathrm{HNO}_{3}-82 \mathrm{H}_{2} \mathrm{O}$ (by wt.\%) (for $\approx 10 \mathrm{~min}$. at $23^{\circ} \mathrm{C}$ ) to contaminate the tube outer-diameter (OD) surface with $\mathrm{F}$. $\mathrm{HP}$ absorber specimens were immersed for $10 \mathrm{~min}$. in a solution of $10 \mathrm{HF}-15 \mathrm{HNO}_{3}-75 \mathrm{H}_{2} \mathrm{O}$ (by wt.\%). The results were compared to those of the specimens tested in as-received condition. Figure 20 shows examples of the significant effect of $\mathrm{F}$ contamination on stress- 
strain behavior. Fracture surface morphology of these specimens was analyzed by SEM to determine percent IGSCC, and the results are summarized in Fig. 21 . The F effect manifested by either total strain or \%IGSCC agrees well.

The $\mathrm{F}$ effect seems to be more significant in HP heats than in CP heats. In Fig. 21(B), specimens irradiated to $1.4 \times 10^{21} \mathrm{n} \mathrm{cm}^{-2}$ exhibited saturation of susceptibility even without $F$ contamination. In our SSRT test on tubular neutron absorber specimens, \%IGSCC higher than $\approx 80 \%$ was never observed; the last portion of fracture surface produced just before fracture always appears to be ductile. The effect of $F$ contamination was negligible in the CP heat irradiated to a fluence of $\approx 0.6 \times 10^{21} \mathrm{n} \mathrm{cm}^{-2}$ (Fig. 21A). For fluence $<0.6 \times 10^{21} \mathrm{n} \mathrm{cm}^{-2}$, \%IGSCC was negligible for this heat under all conditions tested, with or without $\mathrm{F}$ contamination at $\mathrm{DO}$ between $\approx 0.01$ to $\approx 8 \mathrm{ppm}$. This indicates that grain-boundary $\mathrm{Cr}$ depletion in the material is negligible, and when $\mathrm{Cr}$ depletion is negligible, the effect of fluorine seems to be insignificant. This is consistent with the results on nonirradiated materials in which fluorine-induced acceleration of IGSCC was significant only in sensitized steels. ${ }^{30-37}$ In summary, the results of the SSRT tests on Fcontaminated BWR-irradiated neutron absorber tubes indicate a trend that is consistent with the $\mathrm{F}$ effects reported for IGSCC in unirradiated sensitized stainless steels.

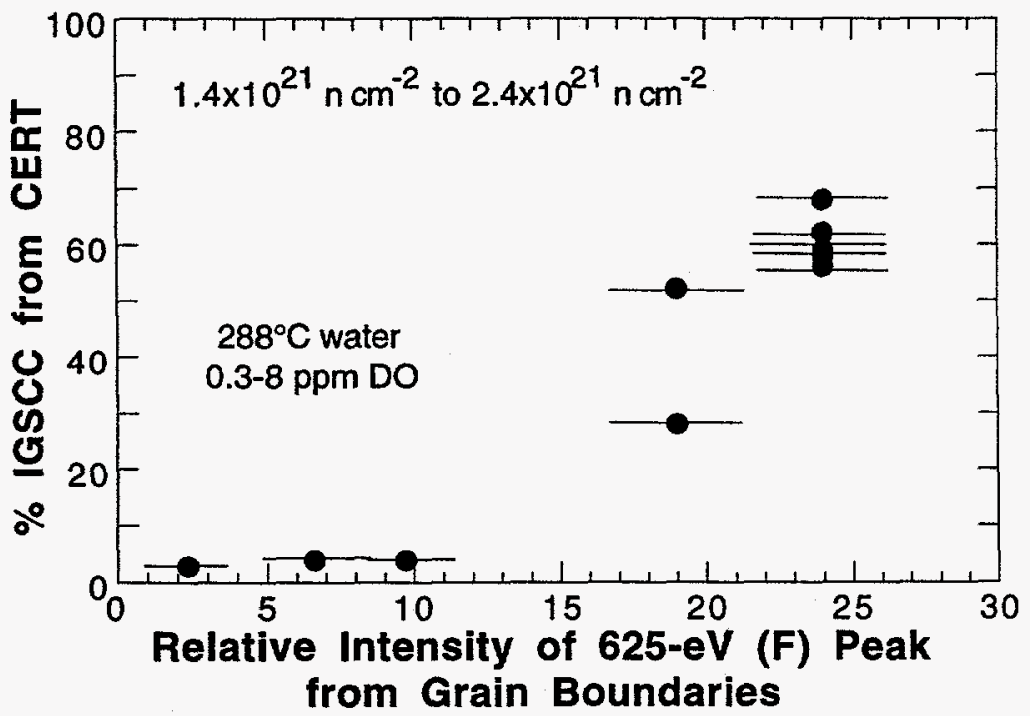

Figure 19.

Percent IGSCC vs. relative intensity of $F$ 625-eV peak from grain boundaries of irradiated BWR components.

\section{Effect of Bulk Oxygen in Steels}

Because of very low solubility in austenitic stainless steels, $O$ is likely to segregate to grain boundaries and increase the free energy of grain boundaries very significantly. However, true $O$ concentration on grain boundaries cannot be measured either by AES or the FEG-AAEM energy dispersive spectroscopy (EDS) technique. Therefore, bulk $O$ content in BWR components was determined by a combined technique of chemical and AES analyses.

Oxygen profile in a specimen was determined as function of distance from IG fracture surface by a depth-profiling technique in which computer-controlled sputtering was conducted with argon ions. 7,8 Typically, the $O$ signal is high on or near a grain boundary, gradually reaching a saturated level at a sputter depths of $>4 \mathrm{~nm}$. The high $O$ level on grain boundaries could be due to contamination from the vacuum environment of the Auger electron microscope or to thermal or irradiation-induced segregation. These effects cannot be separated; therefore, true $O$ concentration on grain boundaries cannot be determined by AES. It cannot be determined either by FEG-AAEM EDS because X-ray emission in EDS is not sensitive to $O$. Therefore, bulk $O$ contents of a few materials were measured from independent chemical analysis and the data were used to calibrate the bulk O levels measured by AES depth-profiling. In this way, bulk $O$ contents in the several heats 
listed in Table 1 were determined. The results were correlated with \%IGSCC measured on the same heats irradiated to a comparable fluence level of $\approx 2 \times 10^{21} \mathrm{n} \mathrm{cm}^{-2}$; this is shown in Fig. 22.
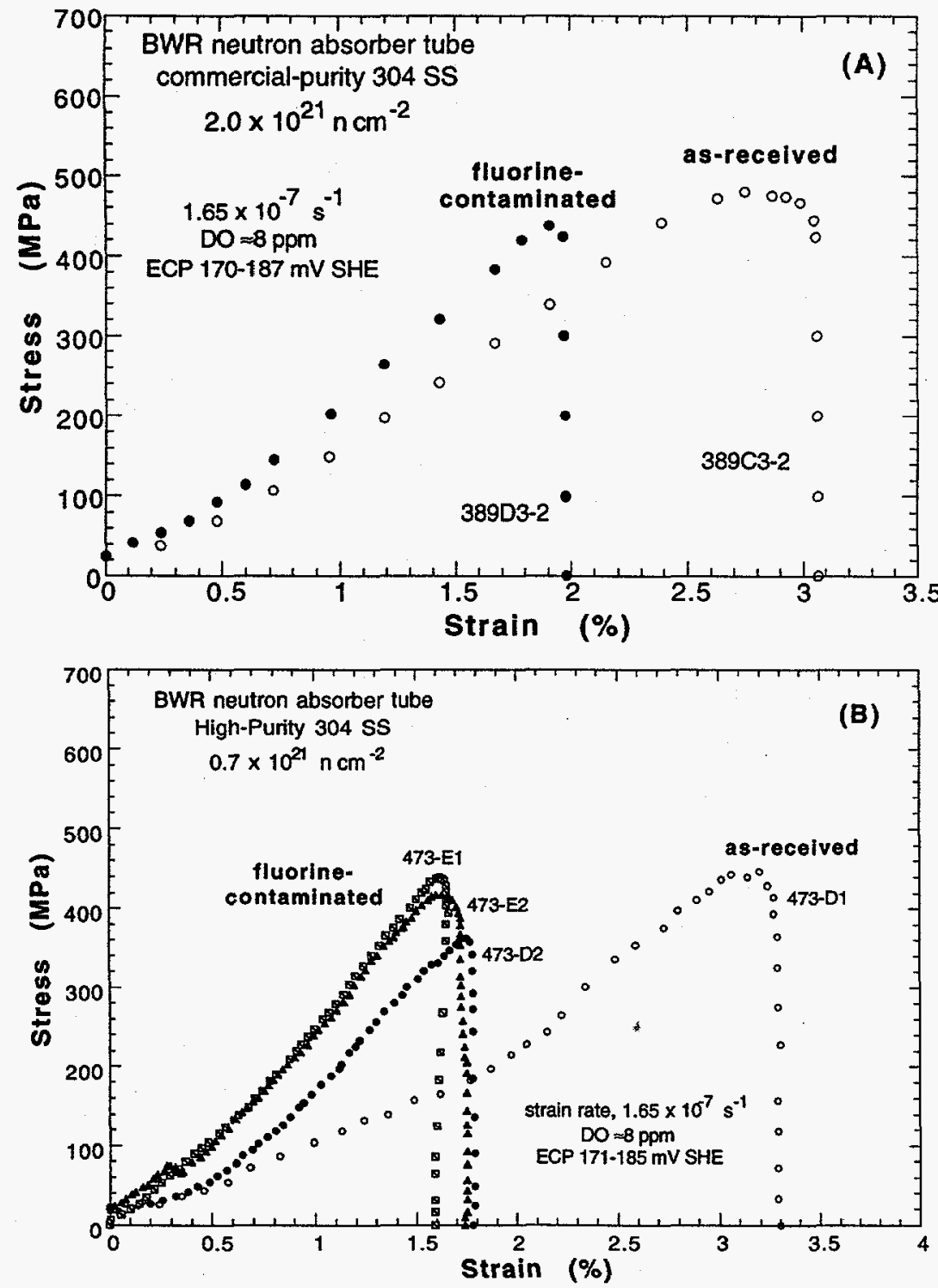

Fig. 20.

Effect of $F$

contamination in BWR

neutron absorber tubes (immersed in HFcontaining solution) on stress-strain behavior in BWR-simulated water (DO $\approx 8 \mathrm{ppm}$ ); (A) CP Type $304 \mathrm{SS}$ (Heat CP304-A) irradiated to $2.0 \times 10^{21}$ $n \mathrm{~cm}^{-2}$ (E > $1 \mathrm{MeV}$; (B) HP Type $304 \mathrm{SS}$ (Heats HP304-A, -B, and $-C D$ ) irradiated to $0.7 \times 10^{21} \mathrm{n} \mathrm{cm}^{-2}$.

The apparently good correlation shown in Fig. 22 indicates a deleterious role of 0 . At this time, however, it is difficult to understand the underlying mechanism, and further investigation is necessary. Higher $O$ in bulk material is conducive to precipitation of oxides or spinels, which could promote crack nucleation.18,29 However, it cannot explain how intergranular cracking is promoted rather than ductile or transgranular cracking. Although other precipitates (such as sulfides and carbides) are also expected to promote crack nucleation in a similar manner, such evidence has been not observed. One other possible explanation is a synergism between $\mathrm{O}, \mathrm{Cr}$, and $\mathrm{F}$. That is, when $\mathrm{O}$ is high in grain matrices, and hence on grain boundaries, $\mathrm{Cr}$ and $\mathrm{O}$ are bound chemically on crack tip surfaces exposed to water. This will prevent $\mathrm{Cr}$ from participating in the fast reaction of

$$
\mathrm{Cr}-\mathrm{F} \text { ( } \mathrm{F} \text { adsorbed })+5 \mathrm{H}_{2} \mathrm{O}=\left[\mathrm{CrF}\left(\mathrm{H}_{2} \mathrm{O}\right)_{5}\right]^{+}+\mathrm{e}^{-}
$$




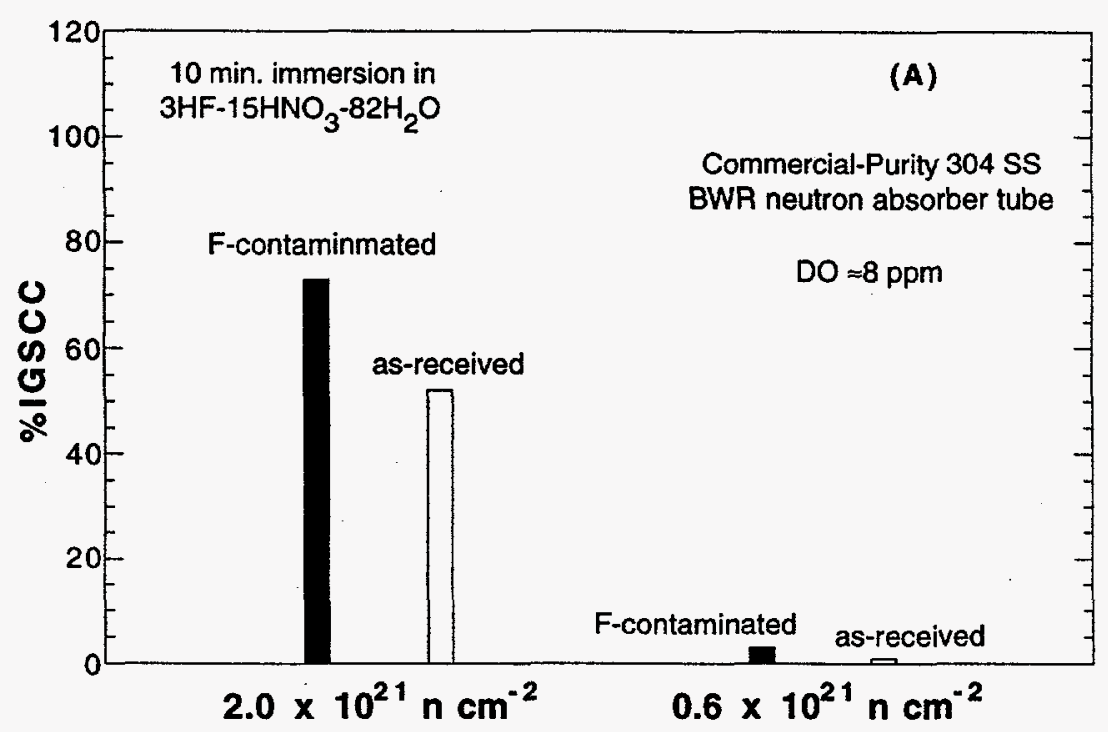

Fig. 21.

Effect of fluorine contamination in BWR neutron absorber tubes (immersed in HF-containing solution) on susceptibility to IGSCC; (A) commercial-purity

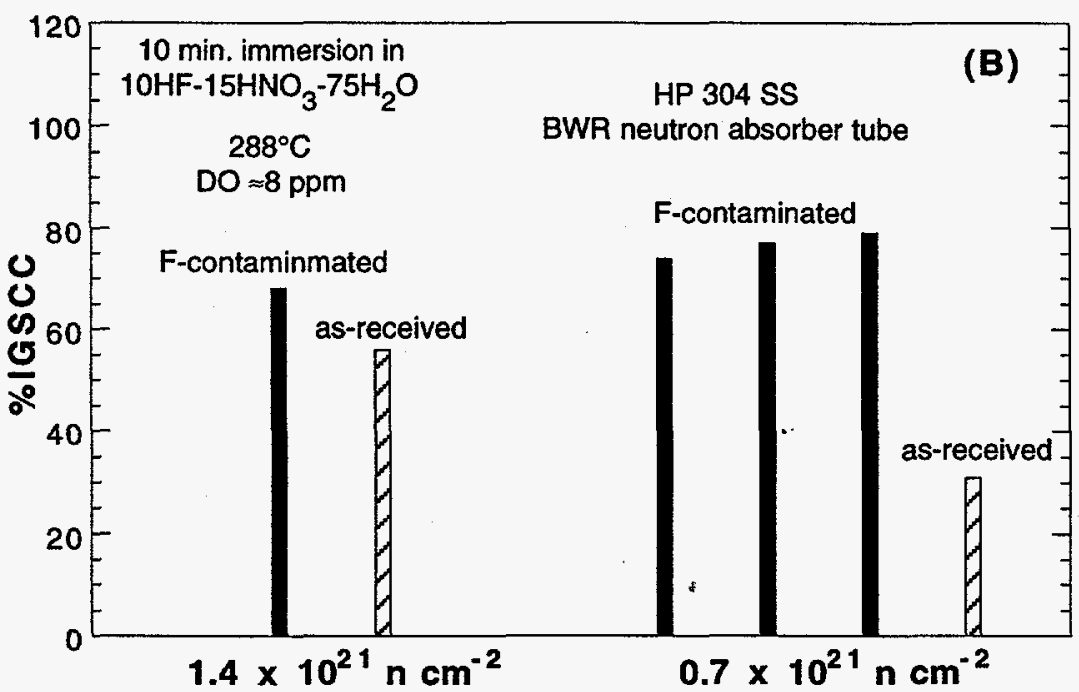
Type 304 SS (Heat CP304-A); (B) highpurity Type 304 SS (Heats HP304-A, $-B$, and $-C D$ ). Fast fluence (E> $1 \mathrm{MeV}$ ) is given for each set of specimens.

This is in effect equivalent to grain-boundary $\mathrm{Cr}$ depletion because concentration of $\mathrm{Cr}$ ions dissolved in water will be low. Then, the catalytic role of $F$ will be in full force. According to this model, a material would be highly susceptible to IASCC if it exhibits the following conditions: (1) contaminated with $F$ and $O$ and (2) grain boundaries depleted of $\mathrm{Cr}$ either by thermal sensitization or irradiation-induced process.

\section{Summary and Conclusions}

The conclusions from this work and the present state of understanding of the effects of the various metallurgical processes and impurities on the susceptibility to IASCC are summarized in Table 2.

It seems obvious that IASCC must be viewed as a complex and integral problem that involves many variables that are influenced strongly not only by the irradiation conditions and stress state but also by the iron- and steelmaking processes, fabrication of the basemetal component, and joining and welding. Synergism among many of these variables is not well understood at present. Therefore, the relative strengths of the separate effects summarized in Table 2 can vary significantly from material to material. 


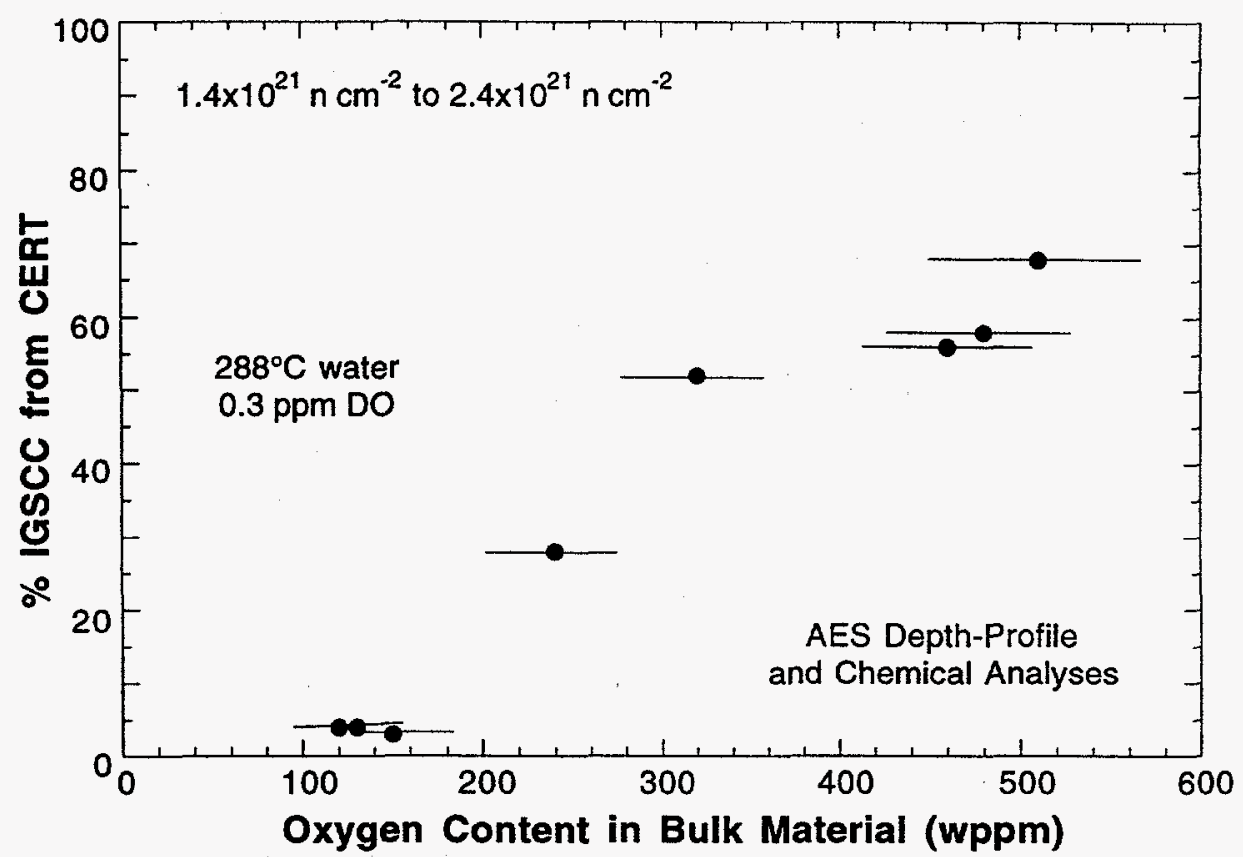

Fig. 22. Bulk oxygen content vs. \%IGSCC of BWR neutron absorber tubes and control blade sheath irradiated to a fluence of $\approx 2 \times 10^{21} \mathrm{n} \mathrm{cm}^{-2}$.

Table 2. Summary of conclusions and present state of understanding of separate effects of metallurgical processes and impurity elements on susceptibility of core-internal components fabricated from austenitic stainless steels.

- Water Environment

- Grain Hardening

- Irradiation-Induced Cr Depletion

- Thermal Segregation of $\mathrm{Cr}$

- $\mathrm{Ni}$

- Mn

- $\mathrm{V}$

- $\mathrm{C}$

- $\mathrm{N}$

- $\mathrm{Si}$

- $\mathbf{P}$

- $\mathrm{S}$

- $\mathrm{F}$

- $\mathrm{O}$

- B
A necessary condition

Deleterious, probably a necessary condition

Deleterious, probably not a necessary condition Beneficial

Higher Ni in bulk delays IASCC

Indirect effect, MnS traps deleterious

impurities but slowly releases them as Mn

transmutes to Fe.

Deleterious

Beneficial

Probably deleterious

Beneficial

Not deleterious

Deleterious

Deleterious

Deleterious

Probably beneficial

Based on the summary given in Table 2, the importance of fabrication-related variables is evident, i.e., grain-boundary segregation and depletion of alloying and impurity elements by thermal process, effect of final thermomechanical treatment, hardening by coldwork, use of recycled scrap metals, and uptake of minor impurities during iron- and steelmaking. 
Special considerations must be also given to avoid contamination of deleterious impurities during welding of core-internal components. Inadvertent contamination of deleterious impurities such as $F$ and $O$ will be dependent largely on the selection of the type of welding. For high-stress components in particular, it would be difficult to mitigate IASCC problems at high fluence based on the consideration of water chemistry alone, and other considerations based on material composition and fabrication procedure would be necessary as well.

\section{Acknowledgments}

The authors would like to thank M. B. McNeil and W. J. Shack for many helpful discussions, D. R. Perkins and D. O. Pushis for experimental contributions, and A. J. Jacobs, R. Kohli, J. L. Nelson, F. Garzarolli, and P. Dewes for supply of irradiated materials.

\section{References}

1. P. L. Andresen, in Stress Corrosion Cracking-Materials Performance and Evaluation, Ed., R. H. Jones, American Soccciety for Metals, p. 182 (1992).

2. P. Scott, J. Nucl. Mater. 211 (1994) 101.

3. A. J. Jacobs, G. P. Wozadlo, K. Nakata, T. Yoshida, and I. Masaoka, in Proc. 3rd Int. Symp. Environmental Degradation of Materials in Nuclear Power Systems - Water Reactors, G. J. Theus and J. R. Weeks, eds., The Metallurgical Society, Warrendale, PA, p. 673 (1988).

4. M. E. Indig, J. L. Nelson, and G. P. Wozadlo, in Proc. 5th Intl. Symp. on Environmental Degradation of Materials in Nuclear Power Systems - Water Reactors. D. Cubicciotti, E. P. Simonen, and R. Gold, eds., American Nuclear Society, La Grange Park, IL, p. 941 (1992).

5. M. Kodama, S. Nishimura, J. Morisawa, S. Shima, S. Suzuki, and M. Yamamoto, ibid., p. 948.

6. K. Fukuya, K. Nakata, and A. Horie, ibid., 814-820.

7. H. M. Chung, W. E. Ruther, J. E. Sanecki, A. G. Hins, and T. F. Kassner, in Effects of Radiation on Materials: 16th Int. Symp. ASTM STP 1175, A. S. Kumar, D. S. Gelles, R. K. Nanstad, and T. A. Little, eds., American Society for Testing and Materials, Philadelphia, p. 851 (1993).

8. H. M. Chung, W. E. Ruther, J. E. Sanecki, and T. F. Kassner, in Proc. 6th Intl. Symp. on Environmental Degradation of Materials in Nuclear Power Systems - Water Reactors, R. E. Gold and E. P. Simonen, eds., The Minerals, Metals, and Materials Society, Warrendale, PA, p. 511 (1993).

9. J. M. Cookson, D. L. Damcott, G. S. Was, and P. L. Anderson, ibid., p. 573.

10. M. Kodama, R. Katsura, J. Morisawa, S. Nishimura, S. Suzuki, K. Asano, K. Fukuya, and K. Nakata, ibid., p. 583.

11. F. Garzarolli, P. Dewes, R. Hahn, and J. L. Nelson, ibid., p. 607.

12. S. Kasahara, K. Nakata, K. Fukuya, S. Shima, A. J. Jacobs, G. P. Wozadlo, and S. Suzuki, ibid., p. 615.

13. R. Katsura, J. Morisawa, M. Kodama, S. Nishimura, S. Suzuki, S. Shima, and M. Yamamoto, ibid., p. 625.

14. M. Kodama, J. Morisawa, S. Nishimura, K. Asano, S. Shima, and K. Nakata, J. Nucl. Mater., 212-215 (1994) 1509.

15. H. M. Chung, W. E. Ruther, and J. E. Sanecki, in Environmentally Assisted Cracking in Light Water Reactors: Semiannual Report, October 1993-March 1994. NUREG/CR4667, ANL-95/2, Vol. 18, March 1995, Argonne National Laboratory, pp. 27-35.

16. M. P. Manahan, R. Kohli, J. Santucci, and P. Sipush, Nucl. Eng. Design, 113 (1989) 297. 
17. K. Hide, T. Onchi, M. Mayuzumi, and K. Dohi, Corrosion 51 (1995) 757.

18. J. M. Cookson and G. S. Was, in Proc. 7th Intl. Symp. on Environmental Degradation of Materials in Nuclear Power Systems - Water Reactors, NACE International, Houston, pp. 1109-1119 (1995).

19. T. Tsukada and Y. Miwa, ibid., 1009-1018.

20. A. J. Jacobs and S. Dumbill, ibid., 1019-1030.

21. K. Asano, R. Katsura, M. Kodama, S. Nishimura, K. Fukuya, and K. Nakata, ibid., 10331042.

22. A. Jenssen and L. G. Ljungberg, ibid., 1043-1052.

23. F. Garzarolli, P. Dewes, R. Hahn, and J. L. Nelson, ibid., 1055-1065.

24. M. Kodama, R. Katsura, J. Morisawa, S. Suzuki, K. Takamori, S. Shima, and T. Kato, ibid., 1121-1132.

25. H. M. Chung, W. E. Ruther, J. E. Sanecki, A. G. Hins, and T. F. Kassner, ibid,. 11331143.

26. I. Suzuki, M. Koyama, H. Kanasaki, H. Mimaki, M. Akiyama, T. Okubo, Y. Mishima, and T. R. Mager, in Proc. ASME JSME 4th Intl. Conf. on Nuclear Engineering, March 1014, 1996, New Orleans, American Society of Mechanical Engineers, 1996, Vol. 5, pp. 205-213.

27. K. Mummert, H. J. Engelmann, S. Schwarz, and M. Uhlemann, in Hydrogen Effects in Materials. The Minerals, Metals, and Materials Society, Warrendale, PA, 1996, p. 679.

28. C. K. Gupta and N. Krishnamurty, Extractive Metallurgy of Vanadium, Elsevier Science, Amsterdam, 1992.

29. H. M. Chung, W. E. Ruther, and A. G. Hins, in Environmentally Assisted Cracking in Light Water Reactors: Semiannual Report. October 1994-March 1995. NUREG/CR4667, ANL-95/41, Vol. 20, January 1996, Argonne National Laboratory, pp. 32-46.

30. C. T. Ward, D. L. Mathis, and R. W. Staehle, Corrosion, 25 (1969) 394.

31. N. C. Huang and Z. Nagy, J. Electrochem. Soc., 134 (1987) 2215.

32. W. E. Berry, E. L. White, and W. K. Boyd, Corrosion 29 (1973) 451.

33. G. J. Theus and J. R. Gels, in Corrosion Problems in Energy Conversion and Generation._C. S. Tedmon, Jr., ed., The Electrochemical Society, 1974, pp. 384-396.

34. P. E. C. Bryant and P. R. Habicht, Fluorine-Induced Intergranular Corrosion of Sensitized Austenitic and Austenoferritic Stainless Steels. Combustion Engineering Internal Report TIS-5065, also in Proc. IAEA Workshop on Stress Corrosion Cracking, March 29-31, 1976.

35. M. Takemoto, T. Shonohara, M. Shirai, and T. Shinogaya, Mater. Perform. 24 (1985) 26.

36. F. Zucchi, G. Trabanelli, and G. Demertzis, Corrosion Science 28 (1988) 69.

37. P. L. Andresen, in Proc." EPRI Workshop on Significance and Control of Chromate in BWRs. Nov. 13-14, 1990, Chicago.

38. C. K. Lee and H. C. Shih, Corrosion 52 (1996) 690. 